\title{
COMPLIANCE CONCORRENCIAL: RELAÇÃO DE CUSTOS E BENEFÍCIOS PÓS LAVA-JATO
}

\section{Carlos Emmanuel Joppert Ragazzo ${ }^{1}$}

\section{Resumo}

A operação denominada "Lava Jato" transformou o Brasil de diversas maneiras. Uma delas foi o aumento do interesse das empresas no desenvolvimento de programas de conformidade capazes de prevenir e de detectar práticas ilícitas, principalmente, aquelas relacionadas a cartéis (parte significativa dos esquemas investigados). Este artigo tem como objetivo investigar, em primeiro lugar, se essa suposta tendência de desenvolvimento dos programas, principalmente os voltados para a prevenção do cometimento de infrações concorrenciais é ou não duradoura, ou se é apenas um evento motivado por uma operação policial e regulatória de grande impacto e, em segundo lugar, de averiguar se esse movimento veio acompanhado da estruturação de programas, de fato, efetivos. A pesquisa conclui que, embora se verifique uma atual tendência à adoção desse tipo de programa, tal movimento ainda precisa passar (no Brasil e no resto do mundo) por um processo de aperfeiçoamento e maturação de estruturas de compliance pouco efetivas, razão pela qual se argumenta que as autoridades públicas ainda não conseguiram calibrar os incentivos corretos para adoção de programas de compliance efetivos.

Palavras-chave: Programas de Compliance; Risco Concorrencial; Custos; Benefícios; Programas Efetivos.

\section{INTRODUÇÃO}

Nos últimos anos, a operação denominada "Lava Jato" mudou o cenário de combate anticorrupção brasileiro, com desdobramentos em penas e infrações administrativas de condutas, principalmente, relacionadas a cartéis (parte significativa dos esquemas adotados). Essa operação conseguiu desvendar subornos dirigidos a campanhas de financiamento de funcionários públicos, subornos esses que teriam sido entregues a políticos em troca de contratos celebrados com Empresas Públicas, objetos de colusão por integrantes do setor. Como resultado preliminar dessa operação, que foi dividida em muitas fases e ainda está em curso $^{2}$, vários empresários e políticos foram presos e montantes consideráveis foram identificados como

\footnotetext{
${ }^{1}$ Professor da Escola de Direito do Rio de Janeiro da Fundação Getúlio Vargas (FGV DIREITO RIO). Doutor pela Universidade do Estado do Rio de Janeiro - UERJ, LL.M. pela New York University School of Law - NYU e Visiting Scholar na University of California at Berkeley. E-mail: carlos.ragazzo@fgv.br

2 A Operação "Lava Jato", que teve início em março de 2014, já conta com mais de 40 fases, além de não haver previsão de seu término. Para mais sobre o funcionamento detalhado da operação, bem como de sua duração, vide: <http://www.mpf.mp.br/para-o-cidadao/caso-lava-jato/entenda-o-caso> e <http://www.pf.gov.br/imprensa/lavajato/fases-da-operacao-lava-jato-1>. Acesso em 17/02/2018.
} 
produto de pagamentos ilícitos.

Esse evento transformou o Brasil de várias maneiras. Antes da "Lava Jato", muitas empresas brasileiras não levavam a sério programas de conformidade anticartel e anticorrupção. Embora a maioria das empresas tivesse uma estrutura de governança em vigor, com um Código de Conduta e um Comitê de Compliance, raramente havia esforços substantivos contra a corrupção realmente realizados. Agora, no entanto, CEOs e Diretores Executivos têm manifestado interesse no desenvolvimento de programas de conformidade, a fim de, efetivamente, prevenir e/ou detectar práticas ilícitas ${ }^{3}$, procurando aconselhamento jurídico e organizacional para desenvolver tais programas ${ }^{4}$. Esse tem sido, ao menos, o movimento aparente de inúmeras empresas brasileiras.

Como essa é uma visão superficial de programas de compliance, é necessário, em um primeiro momento, identificar se essa suposta tendência de desenvolvimento dos programas, principalmente os voltados para a prevenção do cometimento de infrações concorrenciais (ao lado de outras associadas, como corrupção), é duradoura, ou se é apenas um evento motivado por uma operação policial e regulatória de grande impacto, que poderá acabar num futuro próximo. Essa pergunta é particularmente relevante, pois os órgãos regulatórios e policiais devem tê-la em mente para criar os incentivos adequados para que o setor privado adeque suas práticas, contribuindo para a construção de um cenário saudável de concorrência. Nesse sentido, a indução de programas de compliance é uma política pública que deve ser de tempos em tempos avaliada para verificar em que medida deve ser alterada e em que termos.

Em um segundo momento, também é fundamental qualificar esse movimento pela adoção contínua de programas de compliance. Se realmente existe uma tendência do setor privado no sentido de estruturar programas de compliance, é importante saber se há ou não incentivo para estruturar programas efetivos. Isso porque, para a real construção de um cenário concorrencial mais vigoroso, não bastaria que se verificasse a adoção generalizada de estruturas de conformidade, mas sim que esse movimento venha acompanhado do real comprometimento do mercado com a implementação de programas de compliance concorrencial efetivos.

Em termos metodológicos, como forma de se endereçar os dois questionamentos desenvolvidos acima, pretende-se, inicialmente, analisar três variáveis que, fundamentalmente, condicionam a adoção de programas de compliance: (i) os riscos da não conformidade, (ii) os benefícios da conformidade e (iii) os

\footnotetext{
${ }^{3}$ Vide, por exemplo, DINO. Cresce o número de empresas que adotam programas de Compliance em BH, segundo pesquisa da Amcham. Terra. Publicado em: 13/09/2017Disponível em: https://www.terra.com.br/noticias/dino/cresce-o-numerode-empresas-que-adotam-programas-de-compliance-em-bh-segundo-pesquisa-daamcham,d7ff399829607578a190dbf3d8250587ylnirqs4.html. Acesso em: 27/01/2018.

${ }^{4}$ MELO, Luísa; ALVARENGA, Darlan. Compliance vira mercado em alta para escritórios de advocacia e consultorias. G1. Publicado em 09/07/2017. Disponível em: https://gl.globo.com/economia/negocios/noticia/compliance-vira-mercadoem-alta-para-escritorios-de-advocacia-e-consultorias.ghtml. Acesso em: 27/01/2018.
} 
custos de implementação de uma estrutura de conformidade. Afinal, a adoção, ou não, dessa espécie de programa consiste, necessariamente, em uma decisão financeira e estratégica, pois implica realizar um exercício de sopesamento entre uma série de custos necessários à sua efetiva implementação e de potenciais benefícios decorrentes de sua adoção.

Para verificar se realmente existe uma tendência à adoção de programas de conformidade, este artigo traça, preliminarmente, um panorama acerca dos atuais riscos concorrenciais atrelados à atividade econômica empresarial. Tal panorama será construído a partir de dados fornecidos pelo Conselho Administrativo de Defesa Econômica - CADE sobre o número de procedimentos administrativos instaurados, bem como de leniências e termos de compromissos de cessação celebrados entre particulares e CADE. A ideia é identificar se o movimento de investigação é algo limitado à Lava Jato ou resultado de um processo que vem em crescimento por outros fatores.

Traçado esse panorama, que influencia diretamente a decisão entre adotar, ou não, programas de compliance concorrencial, o artigo procura investigar qual é a equação de custos e benefícios associada a essa decisão. No caso, a depender da evolução progressiva do grau de risco do não compliance e da origem e sustentação desse risco, os benefícios atrelados à estruturação desses programas de conformidade também podem se tornar progressivamente mais altos, fato que, consequentemente, dá suporte ao surgimento de uma tendência contínua e duradoura pela adoção desses programas.

Entretanto, diversas outras ideias são indispensáveis para realmente entender essa equação e, consequentemente, se a tendência de investimento em programas de compliance irá continuar e em que medida nos próximos anos. Nesse caso, também se faz necessário analisar (i) quais são as características essenciais que programas de compliance antitruste deveriam possuir (conforme orientações de diversas autoridades antitruste internacionais) e (ii) quais são os custos decorrentes dessas características (conforme publicações de consultorias estrangeiras especializadas) como forma de avaliar em que medida esses investimentos têm, ou não, capacidade de inviabilizar um movimento permanente de estruturação de programas de compliance antitruste.

Por fim, ainda dentro do contexto dos gastos com essas estruturas, se pretende identificar (também a partir de publicações de consultorias estrangeiras especializadas), se a tal suposta tendência de adoção de programas de compliance é um movimento qualificado na direção de políticas efetivas. Conforme adiantado, não basta que exista uma dinâmica de adoção generalizada do compliance, sem que tal fluxo esteja acompanhado das melhores práticas de conformidade possíveis. Nesse ponto, essa análise é fundamental, pois os órgãos regulatórios devem levá-la em consideração para criação não só de incentivos para adoção de programas de conformidade, como também de incentivos para adoção de programas efetivamente capazes de prevenir a prática de atos ilegais e de instituir um contexto mais ético e mais saudável à livre concorrência. 


\section{MODULANDO OS BENEFICIOS PARA COMPLIANCE: TENDENCIA DE RISCO CONCORRENCIAL}

No que se refere ao espectro regulatório concorrencial, o risco do não compliance se exprime essencialmente pela atividade repressiva das autoridades antitruste, i.e., aquela ligada ao controle de condutas anticompetitivas ${ }^{5}$. No contexto específico nacional, duas são as proxies iniciais a serem observadas para captar a atividade repressiva da autoridade antitruste brasileira (Conselho Administrativo de Defesa Econômica CADE): (i) a quantidade de inquéritos administrativos ("IAs") abertos/julgados e (ii) a quantidade de processos administrativos ("PAs") abertos/julgados.

Mas, na realidade, dois outros dados também podem ser levados em consideração para identificar essa atividade de enforcemente, portanto, risco: a quantidade (i) de acordos de leniência e (ii) de termos de compromisso de cessação (TCCs) firmados com o CADE também são bons parâmetros de captação do risco concorrencial na medida em que se tratam de acordos celebrados entre infratores da ordem econômica e órgão antitruste. No caso do acordo de leniência, o infrator que faz jus a ele recebe o benefício da imunidade administrativa e penal total, enquanto que, no caso do TCC, o infrator que faz jus ao requerimento confessa e se compromete a recolher uma contribuição pecuniária ao Fundo de Defesa de Direitos Difusos, mas não recebe benefícios penais.

Em relação especificamente à evolução da quantidade de acordos de leniência firmados entre particulares e o CADE, o gráfico 1, abaixo, capta bem em que medida o risco do não compliance concorrencial têm aumentado ao longo dos anos:

\section{Gráfico 1: Evolução do Número de Acordos de Leniência ${ }^{6}$}

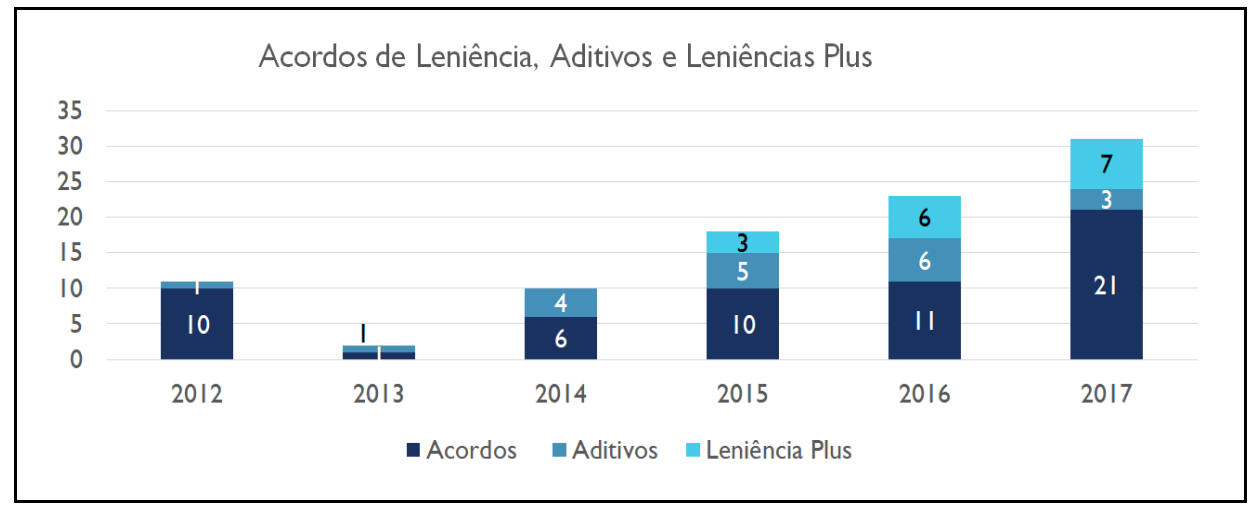

Fonte: $\mathrm{CADE}$

\footnotetext{
${ }^{5}$ Tradicionalmente, é possível se identificar dois tipos de controle exercidos por autoridades de defesa da concorrência em geral. O primeiro diz respeito ao controle de atos de concentração, que tem caráter preventivo (conforme o art. 88 da Lei 12.529/11). O segundo, ao controle de condutas anticompetitivas/infrações econômicas, que tem caráter repressivo (conforme o art. 36 da Lei 12.529/11).
} 
No caso, os acordos de leniência são um forte indicador da atividade de um órgão antitruste, pois reduzem os custos de enforcement da agência concorrencial e aumentam a probabilidade de uma atividade de investigação resultar em condenação, já que um envolvido na suposta conduta anticompetitiva confessa a infração e apresenta provas em relação a terceiros que também participaram da colusão. Embora o aumento do número de leniências esteja sim associado à operação Lava Jato e desdobramentos, o risco endógeno criado a partir da popularização do instrumento parece ser medida sem volta, já que, inicialmente, as leniências estavam majoritariamente focadas em investigações internacionais, não sendo mais esse o caso a partir dos últimos anos ${ }^{7}$.

A mesma tendência pode ser identificada no que diz respeito aos termos de compromisso de cessação, que também vem apresentando movimento de crescimento ao longo dos últimos cinco anos, conforme o gráfico 2 abaixo. No entanto, é importante chamar a atenção para o fato de que esse processo não está limitado aos casos oriundos da operação Lava Jato ${ }^{8}$. Na verdade, o processo de negociação de acordos foi incentivado pela Resolução no 5/2013 que gerava incentivo para uma resolução mais célere de processos em caso de colaboração e confissão, transformando o acordo em um instrumento de investigação mais a molde de uma leniência, dando em contrapartida descontos que podem variar de percentuais baixos até $50 \%$ da multa.

\section{Gráfico 2: Evolução do Número de TCCs Homologados 9}

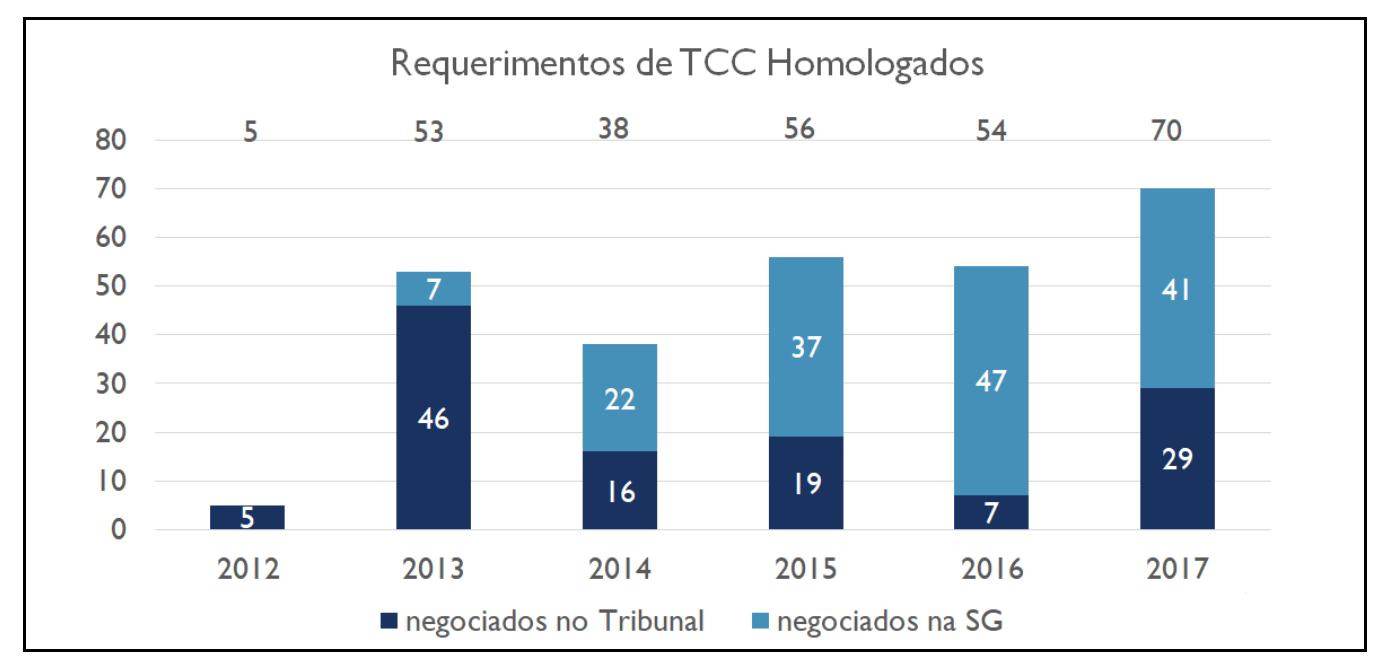

Fonte: $\mathrm{CADE}$

\footnotetext{
${ }^{6}$ SUPERINTENDÊNCIA - GERAL (CADE). Balanço Anual 2017, 2018.

${ }^{7}$ Conforme dados oficiais do CADE, durante a Lei 8.884/94 (período entre 2000 a maio de 2012), mais de 60\% dos Acordos de Leniência dizia respeito a cartéis internacionais (todo ou em parte). Já na vigência da Lei 12.529/11 (período entre junho de 2012 a maio de 2017), mais de $80 \%$ diz respeito dos acordos diz respeito a cartéis nacionais (todo ou em parte).

${ }^{8}$ Somente 14 de todos os acordos firmados entre 2016 e 2017 dizem respeito à Operação Lava Jato. Disponível em: <http://www.cade.gov.br/noticias/cade-investiga-carteis-em-licitacoes-de-infraestrutura-e-transporte-rodoviario-em-sp>. Acesso em: 17/02/2018.
} 
Aliás, esse instrumento tem se mostrado bastante efetivo. Muito embora a quantidade de IAs e PAs julgados tenha decrescido entre 2016 e 2017, a quantidade de requerimentos de TCC julgados, em 2017, aumentou cerca de $23 \%$ em relação a 2016, resultado esse que permite supor um aumento da disposição do particular em firmar acordos com o CADE, justamente, em função do crescimento de um receio quanto à imposição de severas multas administrativas. Assim, o gráfico abaixo parece exprimir que o risco do não compliance concorrencial, ao menos nos dois últimos anos, aumentou:

\section{Gráfico 3: Quantidade de IAs, PAs e TCCs em 2016 e $2017^{10}$}

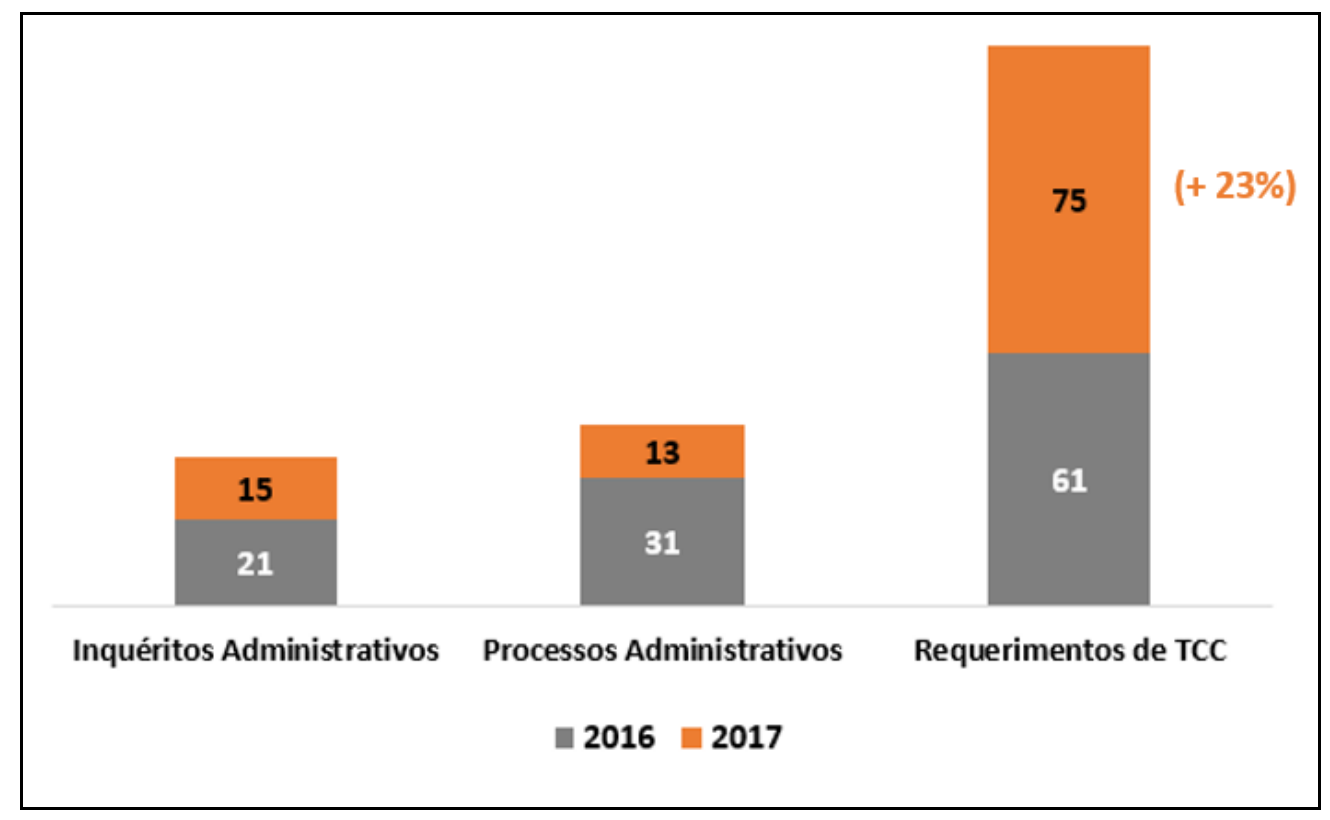

Fonte: CADE em números

Logicamente, uma conjuntura como a descrita nesta seção cria mais incentivos para adoção de programas com objetivo de minorar o risco do cometimento de infrações e, consequentemente, de sofrimento de punições. Afinal, se a prevenção de sanções se traduz em custos evitados, os benefícios atrelados aos programas de compliance tornam-se proporcionalmente mais atrativos em função do aumento do risco do não compliance concorrencial. Com essa lógica em vista, a seção, abaixo, analisa mais profundamente que tipos de benefícios esses programas tendem a gerar para as empresas.

\section{PRIMEIRO COMPONENTE DA EQUAÇÃO: BENEFÍCIOS DO COMPLIANCE CONCORRENCIAL}

À primeira vista, a finalidade dos programas de compliance é dupla: (i) a empresa disponibiliza aos

\footnotetext{
${ }^{9}$ SUPERINTENDÊNCIA - GERAL (CADE). Balanço Anual 2017, 2018.

${ }^{10} \mathrm{CADE}$ em números. Última consulta em 03/02/2018
} 
funcionários um ambiente em que eles podem resolver suas dúvidas e compartilhar experiências sobre os desafios do negócio do dia-a-dia, identificando e prevenindo a prática de condutas que podem ser consideradas ilegais; e (ii) a empresa deixa claro para os funcionários que eles não podem e não serão punidos de forma alguma por relatar atividades ilegais realizadas dentro, ou em nome da empresa. Nesse sentido, portais de dúvidas são criados, bem como canais específicos para denúncia da prática de condutas ilegais (internos e externos).

No entanto, o aspecto informacional e preventivo não seria o único objetivo do compliance concorrencial. O Guia CADE para Programas de Compliance do CADE e o Antitrust Compliance Toolkit da International Chamber of Commerce (ICC), por exemplo, destacam também a criação de uma cultura ética como fim a ser perquirido por esse instituto. Assim, o Guia do CADE ressalta que o "objetivo último do compliance é criar uma cultura de respeito à legislação ${ }^{\prime I}$ e a publicação da ICC destaca que a motivação de cumprimento da lei antitruste seria o desejo de conduzir os negócios com ética e ser reconhecido como fazendo isso ${ }^{12}$. A partir da criação dessa cultura ética para a prática de negócios uma série de benefícios apareceria para as empresas.

Na realidade, a criação dessa cultura de ética negocial (fim último de um programa) é que teria o potencial de criar uma atmosfera de conscientização de funcionários, atmosfera essa que possibilitaria a identificação antecipada da prática de condutas anticoncorrenciais e, consequentemente, a prevenção do risco de cometimento dessas condutas. Todas essas consequências da gênese da cultura ética negocial, aliás, são destacadas por diversas publicações internacionais como benefícios atrelados à adoção de programas de compliance antitruste. Nesse sentido, veja-se, na tabela abaixo, as diversas vantagens que algumas autoridades antitruste atribuem ao instituto:

\footnotetext{
${ }^{11}$ MINISTÉRIO DA JUSTIÇA. CONSELHO ADMINISTRATIVO DE DEFESA ECONÔMICA. Guia para Programas de Compliance. Brasília, 2016, p.10. Disponível em: <http://www.cade.gov.br/acesso-a-informacao/publicacoesinstitucionais/guias_do_Cade/guia-compliance-versao-oficial.pdf>. Acesso em: 17/01/2018.

${ }^{12}$ INTERNATIONAL CHAMBER OF COMMERCE. THE ICC ANTITRUST COMPLIANCE TOOLKIT: Practical antitrust compliance tools for SMEs and larger companies. 2013, prefácio. Disponível em: <https://iccwbo.org/publication/icc-antitrust-compliance-toolkit/>. Acesso em: 17/01/2018.
} 


\section{Tabela 1: Benefícios atrelados à adoção de programas de compliance concorrencial ${ }^{13}$}

\begin{tabular}{|c|c|c|c|c|c|c|c|c|}
\hline Autoridade & $\begin{array}{l}\text { Identificação } \\
\text { antecipada/ } \\
\text { prevenção do } \\
\text { cometimento } \\
\text { de práticas } \\
\text { ilícitas }\end{array}$ & $\begin{array}{l}\text { Melhora da } \\
\text { reputação da empresa } \\
\text { perante funcionários } \\
\text { e } \\
\text { clientes/fornecedores }\end{array}$ & $\begin{array}{c}\text { Redução de } \\
\text { custos e } \\
\text { contingências }\end{array}$ & $\begin{array}{l}\text { Possível } \\
\text { causa } \\
\text { de } \\
\text { redução } \\
\text { de pena }\end{array}$ & $\begin{array}{l}\text { Conscientização } \\
\text { dos funcionários }\end{array}$ & $\begin{array}{l}\text { Conscientização } \\
\text { dos } \\
\text { concorrentes, } \\
\text { fornecedores e } \\
\text { clientes }\end{array}$ & $\begin{array}{l}\text { Reconhecimento } \\
\text { de ilicitudes } \\
\text { cometidas por } \\
\text { terceiros }\end{array}$ & $\begin{array}{c}\text { Fator de } \\
\text { crescimento } \\
\text { da empresa }\end{array}$ \\
\hline Brasileira & $\mathrm{X}$ & $X$ & $X$ & $X$ & $X$ & & $X$ & \\
\hline Europeia & $\mathrm{X}$ & $X$ & $\mathrm{X}$ & & $X$ & & $X$ & \\
\hline R. Unido & $X$ & $X$ & & $\mathrm{X}$ & & $X$ & & $X$ \\
\hline Francesa & $\mathrm{X}$ & $X$ & $X$ & & & & & $X$ \\
\hline Turca & $X$ & $X$ & & & $X$ & & & \\
\hline
\end{tabular}

Fonte: elaboração própria.

A partir da tabela acima, é possível notar que a identificação antecipada do cometimento de práticas ilícitas e a melhora da reputação das empresas são benefícios elencados por todas as publicações de autoridades antitruste analisadas. Entretanto, é curioso notar também como parece não haver essa mesma homogeneidade em relação a outros fatores que somente algumas publicações consideram como sendo benefícios associados à adoção de programas de compliance concorrencial. Como exemplos dessa diversificação de benefícios, basta analisar os itens "redução de custos e contingências" e "possível causa de redução de pena", elementos que, do ponto de vista exclusivamente financeiro, são relevantes para as empresas, já que se traduzem em sanções pecuniárias evitadas (i.e., custos evitados) bem como possível mitigação dessas sanções.

Efeito reflexo desse objetivo já pode ser visto na evolução do percentual de acordos em relação a outros instrumentos antitruste de enforcement, como o inquérito administrativo e o processo administrativo, demonstrando o papel concreto de programas internos:

\section{Gráfico 4: Representatividade dos TCCs ${ }^{14}$}

\footnotetext{
${ }^{13}$ Ressalte-se que essa tabela, em alguma medida, faz algumas aproximações de determinados posicionamentos das autoridades em relação a cada benefício atrelado aos programas de compliance antitruste. Para uma descrição mais pormenorizada de cada benefício enunciado pelas autoridades constantes na tabela, vide Anexo 1 deste artigo.
} 


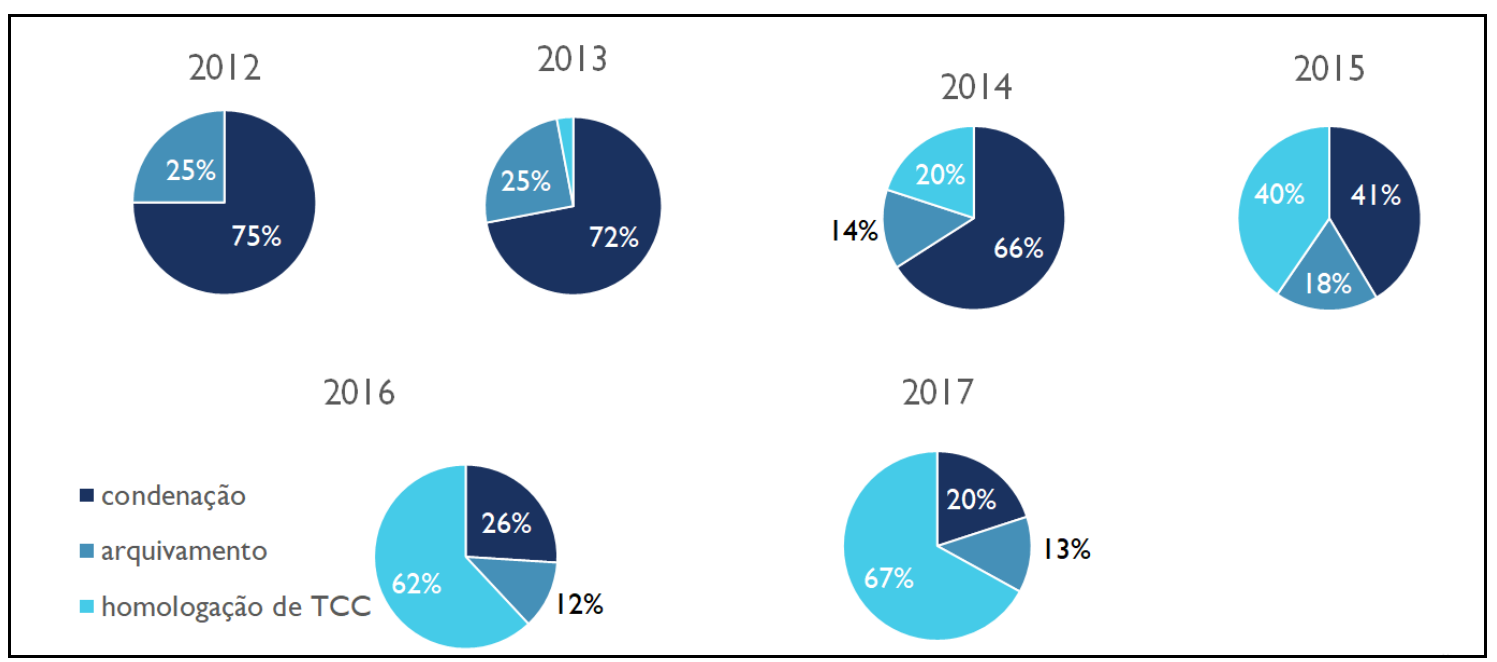

Fonte: $\mathrm{CADE}$

No limite, em função do aumento da quantidade de contribuições arrecadadas via formalização de TCCs com a autoridade concorrencial brasileira, o que se tem é um aumento da atratividade de programas de compliance como forma de remediar custos progressivamente mais altos do não compliance. $\mathrm{O}$ crescimento vertiginoso das contribuições pecuniárias recolhidas em sede de TCC (além do número relativo de termos homologados, como indicado acima) demonstra que o instrumento tem sido objeto de uso cada vez maior por parte de agentes privados, o que comprova o alto valor do benefício de um programa de compliance para a finalidade de redução de multas/contingências:

\section{Gráfico 5: Arrecadação de TCCS ao Fundo de Direitos Difusos - FDD ${ }^{15}$}

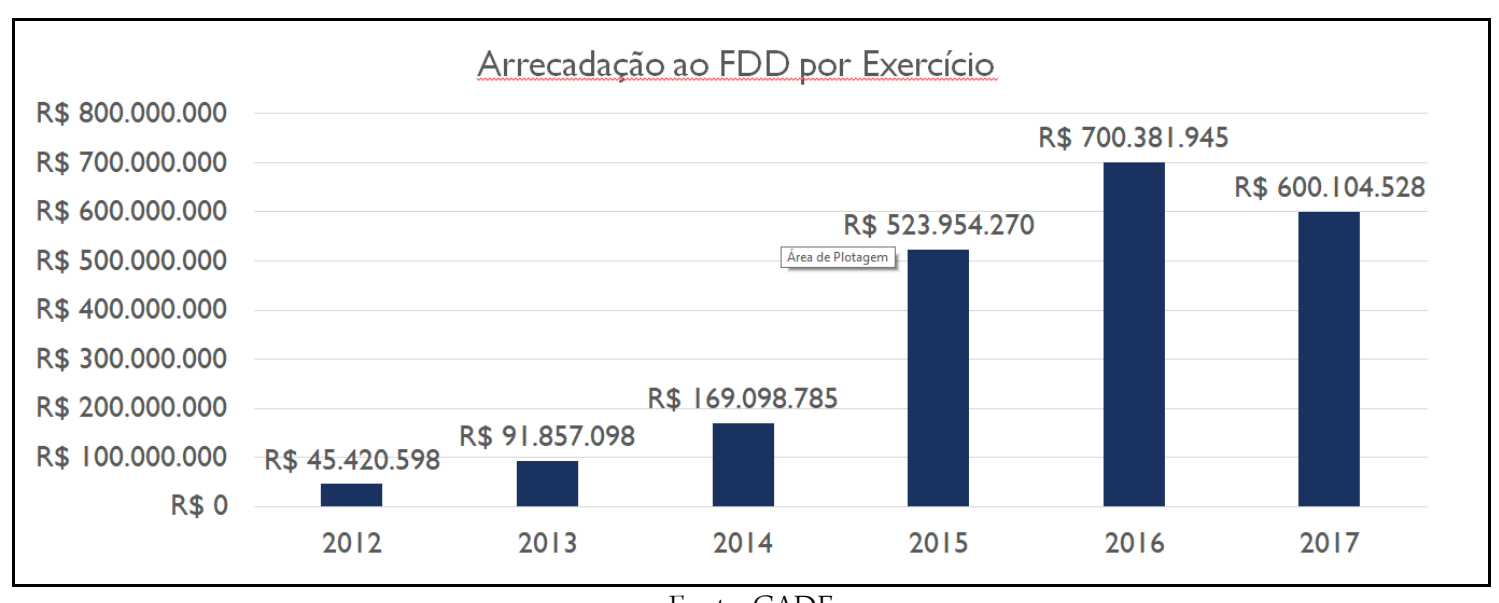

Fonte: $\mathrm{CADE}$

Existem dúvidas, no entanto, com relação à possibilidade de programas de compliance serem utilizados como justificativa para mitigação de sanções, ao contrário das situações acima em que o desconto decorre de

\footnotetext{
${ }^{14}$ SUPERINTENDÊNCIA - GERAL (CADE). Balanço Anual 2017, 2018.

${ }^{15}$ SUPERINTENDÊNCIA - GERAL (CADE). Balanço Anual 2017, 2018.
} 
colaboração. Tal hipótese não é aceita pela totalidade das autoridades antitruste internacionais. E, não bastasse isso, as autoridades de defesa da concorrência que preveem essa oportunidade ainda exigem que o programa seja efetivo, isto é, possua uma série de características capazes de criar uma estrutura realmente capaz de evitar o cometimento de atos infracionais dentro das empresas, o que não é uma tarefa fácil ${ }^{16}$. Assim, embora a possiblidade de mitigação seja um potencial benefício da adoção do compliance concorrencial, fato é que esse benefício necessariamente vem acompanhado de alguns custos de implementação que podem ser não desprezíveis (conforme se demonstrará na próxima seção).

No contexto nacional, a existência de um programa de compliance concorrencial efetivo pode ser considerada como uma evidência de boa-fé a ensejar a atenuação de pena (multa) aplicável, pelo CADE, no curso de um processo administrativo ${ }^{17}$. Essa mitigação é possível dado que o Conselho, ao realizar o escrutínio da aplicação de penas sobre agentes que cometeram infrações econômicas, leva em consideração determinados fatores constantes no art. 45 da Lei 12.529/11, sendo um deles, justamente, a boa-fé do infrator ${ }^{18}$.

Na prática, embora o Guia CADE preveja a possibilidade da mitigação, ainda não é possível se encontrar casos, no Conselho, em que o Tribunal tenha efetivamente mitigado uma sanção ante a existência, na época da infração, de um programa de compliance efetivo por parte do agente econômico infrator ${ }^{19}$. Especificamente em relação ao tema do compliance, é possível encontrar processos em que (i) o CADE impôs a adoção do programa como condição para assinatura de $\mathrm{TCCs}^{20}$, (ii) o CADE sugeriu, quando da aplicação concreta de uma sanção, a adoção dele nos moldes definidos pelo próprio Tribunal ${ }^{21}$ e em que (iii) o CADE concedeu um desconto em

\footnotetext{
${ }^{16}$ Tais caraterísticas serão mais bem analisadas e detalhadas na próxima seção (acerca dos custos dos programas de compliance antitruste), na medida em que se traduzem em custos de implementação dessas estruturas.

${ }^{17}$ MINISTÉRIO DA JUSTIÇA. CONSELHO ADMINISTRATIVO DE DEFESA ECONÔMICA. Guia para Programas de Compliance. Brasília, 2016, p. 42. Disponível em: <http://www.cade.gov.br/acesso-a-informacao/publicacoesinstitucionais/guias_do_Cade/guia-compliance-versao-oficial.pdf>. Acesso em: 17/01/2018.

${ }^{18}$ Art. 45. Na aplicação das penas estabelecidas nesta Lei, levar-se-á em consideração:

I - a gravidade da infração;

II - a boa-fé do infrator;

III - a vantagem auferida ou pretendida pelo infrator;

IV - a consumação ou não da infração;

V - o grau de lesão, ou perigo de lesão, à livre concorrência, à economia nacional, aos consumidores, ou a terceiros;

VI - os efeitos econômicos negativos produzidos no mercado;

VII - a situação econômica do infrator; e

VIII - a reincidência.

${ }^{19}$ Tal constatação pode estar atrelada ao fato de essa orientação ainda ser relativamente recente, dado que o aludido Guia se tornou público somente no início do ano de 2016.

${ }^{20}$ Como exemplo, é possível se citar os TCCs assinados no bojo do Processo Administrativo no 08012.006130/2006-22, do Processo Administrativo no 08012.005024/2011-99 e do Processo Administrativo no 08012.002493/2005-16.

${ }^{21}$ É possível encontrar casos em que, a priori, o Tribunal deseja impor a adoção de programas de compliance (como uma espécie de sanção pecuniária), a posteriori, reconhece que o enforcement do programa por parte do Conselho seria inviável ou até mesmo que tal hipótese de sanção não estaria prevista na lei concorrencial, não aplicando, então, a adoção do programa como punição específica à prática de infração à ordem econômica. Para mais sobre esse tema consultar votos constantes no Processo Administrativo no 08012.000504/2005-15 e Processo Administrativo no 08012.010744/2008-71.
} 
função do compromisso do particular em adotar (dentre outras obrigações) um programa de compliance. ${ }^{22}$

Alternativamente ao posicionamento da autoridade de defesa da concorrência brasileira, a Comissão da União Europeia tem clara opção no sentido de não conceder reduções de pena, não obstante a existência de programas de compliance efetivos. Desde 2010 (a partir do discurso do o então vice-presidente e responsável pela política de concorrência da autoridade, Joaquín Almunia ${ }^{23}$ ) até atualmente (com a vigência do Guia de Compliance da Comissão Europeia ${ }^{24}$ ), a postura da Comissão é firme no sentido de não conceder reduções de pena em função da existência, ou criação de programas de compliance antitruste.

Os posicionamentos contrastantes das autoridades brasileira e europeia fazem emergir questionamento importante acerca da temática do compliance antitruste: uma companhia que contava com a existência de um programa de compliance efetivo à época da prática de uma infração concorrencial pode ser recompensada com atenuação de pena? Como explorado, é possível se esperar duas respostas a essa pergunta ("sim”, ou, "não"), respostas às quais é possível se atrelar dois perfis de argumentos.

Por um lado, a negativa dessa pergunta se funda em alegações segundo as quais já existiriam recompensas suficientes para infratores e que os incentivos para adoção do compliance residem nos próprios benefícios de sua adoção (evitar a prática de condutas anticompetitivas e, consequentemente, uma condenação rigorosa). Em contraste, a resposta positiva à pergunta está atrelada a criação de mais um incentivo para adoção desses programas, cujo potencial de evitar o cometimento de infrações a longo prazo é alto além de conferir proporcionalidade a aplicação de sanção a um agente que, de fato, tenha empregado esforços efetivos para prevenir a prática de infrações econômicas ${ }^{25}$

Consoante com publicações que tratam especificamente da possibilidade de redução de pena em função

\footnotetext{
${ }^{22}$ Vide voto do Conselheiro Relator Márcio de Oliveira Júnior no Requerimento de TCC nº 08700.004780/2015-76.

${ }^{23}$ ALMUNIA, Joaquín. SPEECH/10/586 at Businesseurope \& US Chamber of Commerce Competition Conference. Bélgica. 2010. Disponível em: <http://europa.eu/rapid/press-release_SPEECH-10-586_en.htm>. Acesso em: 16/05/2017. Segundo Joaquín: "Quando falo sobre essas coisas, muitas vezes me perguntam se as empresas devem ser recompensadas por operar programas de compliance quando são encontradas envolvidas em práticas comerciais ilegais.

A resposta é não. Não deve haver redução de multas ou outro tratamento preferencial para essas empresas. Como já mencionado, recompensamos a cooperação na descoberta do cartel, recompensamos a cooperação durante os procedimentos perante a Comissão, recompensamos as empresas que tiveram uma participação limitada no cartel, mas isso, acho que já é o suficiente" (traduzido do original).

${ }^{24}$ COMISSÃO EUROPEIA. Compliance matters: What companies can do better to respect EU competition rules. Luxembourg: Publications Office of the European Union, Europa, 2012. p 21. Disponível em: <http://ec.europa.eu/competition/antitrust/compliance/index_en.html>. Acesso em: 16/05/2017. Conforme o guia: "Com o propósito de estabelecer o nível das multas, a situação específica de uma empresa é devidamente levada em consideração. Mas a mera existência de um programa de compliance não será considerada uma circunstância atenuante. Nem a criação de um programa de compliance será considerado um argumento válido que justifique uma redução da multa na sequência da investigação de uma infração" (traduzido do original).

${ }^{25}$ PARCU, Piere Luigi; STASI, Maria Luisa. Antitrust Compliance Programs in Europe: Status Quo and Challenges Ahead. In: Launch Workshop ENTraNCE for Executives, 2016, Florença. Disponível em: <http://cadmus.eui.eu/bitstream/handle/1814/39644/ENTraNCE_PB_2016_01.pdf?sequence=3>. Acesso em: 16/05/2017.
} 
da existência de programas de compliance efetivos ("Compliance Programmes and Antitrust Fines"26 e Compliance Programmes in Competition $\operatorname{Law}^{27}$ ), bem como com os diversos guias analisados ao longo deste artigo, é possível organizar os diferentes posicionamentos das autoridades sobre o assunto da seguinte forma:

\section{Tabela 2: Posturas de autoridades antitruste acerca da possibilidade de mitigação de pena em função da existência de programas de compliance efetivos}

\begin{tabular}{|c|c|c|}
\hline Autoridade & A favor da possibilidade & Contrária à possibilidade \\
\hline Brasileira & $\mathrm{X}$ & \\
\hline Europeia & & $\mathrm{X}$ \\
\hline Americana & $\mathrm{X}$ & \\
\hline Canadense & $\mathrm{X}$ & \\
\hline Reino Unido & $\mathrm{X}$ & \\
\hline Francesa & $\mathrm{X}^{28}$ & \\
\hline Alemã & & $\mathrm{X}$ \\
\hline Holandesa & & $\mathrm{X}^{29}$ \\
\hline Italiana & $\mathrm{X}$ & \\
\hline & Fonte: elaboração própria \\
\hline
\end{tabular}

A análise da tabela 2, acima, reforça a ideia de que não há um consenso entre entidades de defesa da concorrência quanto à possibilidade de mitigação de sanção administrativa em razão da existência de programas de compliance. Enquanto o número de leniências e também de acordos permanece alto, a questão da mitigação ainda parece secundária. Num segundo momento, de estabilização dos números de arrecadação e de investigações (leniências, TCCs, além dos respectivos inquéritos e/ou processos), a redução por conta de programas de compliance efetivos será provavelmente uma questão mais premente no Brasil. O CADE poderá sinalizar de forma mais evidente o apoio a programas de compliance mais efetivos por meio da mitigação, o que pode dar um segundo impulso aos investimentos no instrumento.

\footnotetext{
${ }^{26}$ VANDENBORRE, Ingrid; GOETZ Thorsten. Compliance Programmes and Antitrust Fines. International Comparative Legal Studies, 2017. Disponível <https://awards.concurrences.com/IMG/pdf/2 compliance_programmes and_antitrust fines.pdf $>$. Acesso em 16/05/2017. ${ }^{27}$ LACHNIT, Eva. Compliance Programmes in Competition Law: Improving the Approach of Competition Authorities. Utrecht Law Review, v.10, pp 31-50, 2014.

${ }^{28} \mathrm{Na}$ verdade, no caso específico da autoridade francesa a redução de pena pode vir a ser concedida quando a adoção (ou ajuste) de um programa de compliance é proposta como remédio no curso de uma negociação. Nesse caso, vide AUTORITÉ DE LA CONCURRENCE. Antitrust compliance programmes - Corporate tools for competing safely in competition marketplace. Paris, 2012, p. 10.

${ }^{29}$ A autoridade holandesa além de ser contrária à redução de pena independentemente da existência de programa de compliance, também já considerou a existência de um programa de compliance de fachada como circunstância agravante da pena. Para mais informações, vide VANDENBORRE, Ingrid; GOETZ Thorsten. Compliance Programmes and Antitrust Fines. International Comparative Legal Studies, 2017.p.4.
} 
Entre os benefícios não identificados pelo Guia de Compliance Brasileiro está o reconhecimento do instrumento como fator de crescimento da empresa. Parece que, ao menos até o momento, os agentes privados não reconhecem no programa um fator de diferenciação competitiva que pode ser compreendido e avaliado por consumidores e clientes finais como um verdadeiro fator de decisão. Aliás, esse é um bom termômetro para perceber que o caminho para o desenvolvimento dos programas de compliance no Brasil ainda é longo (conforme se demonstrará no próximo tópico), merecendo contínuo incentivo por parte da agência antitruste e dos demais órgãos reguladores.

\section{SEGUNDO COMPONENTE DA EQUAÇÃO: CUSTOS DE ESTRUTURAÇÃO DO COMPLIANCE}

O reconhecimento de que o compliance concorrencial pode ser custoso tem fundamento na lógica de que os benefícios associados a ele somente se materializam por meio da estruturação de programas efetivos, isto é, de fato capazes de evitar a prática de infrações econômicas. Além das vantagens (tratadas acima como benefícios), as publicações das autoridades também elencam uma série de "características essenciais" que os programas de compliance antitruste devem ter para que alcancem seus objetivos e, consequentemente, proporcionem os benefícios acima listados.

Mas o que representa um programa de conformidade efetivo de acordo com as autoridades brasileiras? Antes de entrar no mérito do que está disposto nos guias, vale a pena passar pelas etapas: em primeiro lugar, as empresas devem identificar seus riscos a esse respeito. Portanto, o oficial de conformidade tem que desenhar o organograma da empresa e, em seguida, elaborar a matriz de risco, sendo este o documento que identifica as áreas em que o risco de colusão na empresa é maior. Ao redor desses riscos, é formatada a estrutura de governança para evitar ilícitos antitruste, com a construção de políticas específicas para a prevenção de condutas anticompetitivas (ou, a depender do perfil de risco aplicável, um código de conduta), além de um comitê de compliance para avaliar as denúncias que chegam a partir do canal interno.

Aliás, um dos principais itens de uma estrutura de governança de conformidade é o canal interno de denúncias. A maioria das principais empresas brasileiras já implantou canais internos para incentivar os funcionários a reportar subornos e outras atividades ilegais realizadas por colegas ou por terceiros envolvidos no negócio das empresas. O canal se tornou em um instrumento primordial para as empresas brasileiras, pois thes dá a chance de identificar a conduta ilegal (às vezes em estágio inicial), possibilitando a colaboração com as autoridades, entre as quais se incluem condutas anticompetitivas.

Mas a discussão começou a se sofisticar. Como dito na introdução, não basta ter um programa de compliance "de gaveta”. Alguns fatores começaram a ser considerados para classificar um programa como efetivo. 
Entre esses fatores, é importante mencionar a constatação de que recursos adequados para as tarefas de compliance é um fator que surge como algo efetivamente relevante. Embora não exista uma fórmula, é possível identificar uma relação entre o número total de funcionários a serem avaliados e o total da equipe dedicada à função. Mas isso não é o suficiente para encerrar essa questão, já que esse número de pessoas deverá ser ponderado pelo risco identificado na matriz, bem como às instrumentalidades tecnológicas utilizadas como opção pelo departamento, tanto para treinamento, como para detecção de condutas anticompetitivas.

A estrutura de mitigação de riscos passa pelas seguintes funções: (i) monitoramento; (ii) canais de denúncia (internos e/ou externos); (iii) ciclos de treinamento (virtual, presencial ou mesmo uma combinação dos dois, o que é preferido, com mecanismos de verificação de aprendizagem; (iv) além de um sistema de punição para funcionários e/ou terceiros denunciados. Além disso, os elementos de governança são igualmente importantes à existência dos instrumentos básicos que a compõem. Ao lado de políticas internas e de pessoal especializado à função (equipe específica), é necessário que exista autonomia no departamento, além de acesso à mais alta camada corporativa, além do seu envolvimento, ao que se comumente chama de comprometimento da alta direção.

No entanto, o esforço de uniformizar os elementos que compõem um programa de compliance efetivo de acordo com as autoridades concorrenciais ainda será significativo. Sobre isso, veja a tabela abaixo com os principais elementos que determinadas agências de defesa da concorrência levam em consideração para caracterizar um programa de compliance como sendo efetivo:

\section{Tabela 3: Características essenciais de programas de compliance antitruste efetivos ${ }^{30}$}

\footnotetext{
${ }^{30}$ Ressalte-se que essa tabela, em alguma medida, faz algumas aproximações de determinados posicionamentos das autoridades em relação à cada caraterística atrelada aos programas de compliance antitruste efetivos. Para uma descrição mais pormenorizada de cada uma das características enunciadas pelas autoridades constantes na tabela, vide Anexo 2 deste artigo.
} 
Fonte: elaboração própria

\begin{tabular}{|c|c|c|c|c|c|c|c|c|c|c|c|c|}
\hline Autoridade & $\begin{array}{l}\text { Compro- } \\
\text { metimento } \\
\text { da alta } \\
\text { direção }\end{array}$ & $\begin{array}{l}\text { Mecanismos } \\
\text { de } \\
\text { penalidades } \\
\text { /incentivos }\end{array}$ & $\begin{array}{l}\text { Criação de } \\
\text { políticas/ } \\
\text { procedimentos } \\
\text { (e.g. guias e } \\
\text { manuais) }\end{array}$ & $\begin{array}{c}\text { Revisão } \\
\text { periódica/realização } \\
\text { de auditorias }\end{array}$ & $\begin{array}{c}\text { Mecanismos } \\
\text { de delaçōes }\end{array}$ & $\begin{array}{c}\text { Mecanismos } \\
\text { de } \\
\text { monitoramento }\end{array}$ & $\begin{array}{l}\text { Realização } \\
\text { periódica de } \\
\text { treinamentos }\end{array}$ & $\begin{array}{l}\text { Mecanismos } \\
\text { de análise } \\
\text { /identificação } \\
\text { de riscos }\end{array}$ & $\begin{array}{l}\text { Autonomia/ } \\
\text { Independência }\end{array}$ & $\begin{array}{l}\text { Criação de } \\
\text { canais } \\
\text { de } \\
\text { comunicação } \\
\text { (e.g dúvidas) }\end{array}$ & $\begin{array}{c}\text { Sistema } \\
\text { contínuo de } \\
\text { avaliação da } \\
\text { aprendizagem }\end{array}$ & $\begin{array}{l}\text { Aplicação } \\
\text { de } \\
\text { recursos } \\
\text { adequados }\end{array}$ \\
\hline Brasileira & $\mathrm{X}$ & $\mathrm{X}$ & $\mathrm{X}$ & $\mathrm{X}$ & $\mathrm{X}$ & & & $\mathrm{X}$ & $\mathrm{X}$ & & & $\mathrm{X}$ \\
\hline Europeia & $X$ & $\mathrm{X}$ & $\mathrm{X}$ & $\mathrm{X}$ & $\mathrm{X}$ & $\mathrm{X}$ & $\mathrm{X}$ & $\mathrm{X}$ & & $\mathrm{X}$ & & \\
\hline Canadense & $\mathrm{X}$ & $\mathrm{X}$ & $\mathrm{X}$ & $\mathrm{X}$ & $\mathrm{X}$ & $X$ & $\mathrm{X}$ & $\mathrm{X}$ & & $\mathrm{X}$ & & \\
\hline R. Unido & $\mathrm{X}$ & $\mathrm{X}$ & $\mathrm{X}$ & $X$ & $\mathrm{X}$ & & $\mathrm{X}$ & $\mathrm{X}$ & & & & \\
\hline Francesa & $\mathrm{X}$ & $\mathrm{X}$ & $\mathrm{X}$ & $\mathrm{X}$ & $\mathrm{X}$ & $\mathrm{X}$ & $\mathrm{X}$ & & $X^{31}$ & $X$ & & \\
\hline $\begin{array}{c}\text { Sul } \\
\text { Coreana }\end{array}$ & $\mathrm{X}^{*}$ & $X$ & $X$ & & & $X$ & & & $X^{32}$ & & $X$ & \\
\hline Japonesa & $X$ & X & & $\mathrm{X}$ & & $\mathrm{X}$ & & & & & & \\
\hline Turca & $X$ & X & $X$ & $\mathrm{X}$ & & & $X$ & & & & $\mathrm{X}$ & \\
\hline
\end{tabular}

Da análise da tabela 3, acima, é possível se extrair que o comprometimento da alta direção, a existência de mecanismos de punição/incentivos, a criação de políticas/procedimentos e a realização de revisões periódicas são qualidades que a grande maioria (senão a totalidade) das autoridades analisadas consideram como fundamentais à estruturação de programas efetivos. Mas talvez o principal custo de um programa de compliance diz respeito à necessidade de contínua evolução para ser considerado efetivo, ao que se soma o elemento da customização ao tamanho da empresa e aos riscos a si relacionados. Mais cedo ou mais tarde todo programa será testado em algum momento de falha, seja porque identificou alguma conduta (mas não a tempo de evitá-la) ou mesmo porque empregados conseguiram efetivamente burlar o sistema, implementando condutas anticompetitivas a despeito do programa.

E o que isso tudo significa em termos de custo? Um conjunto de reports e surveys de consultorias estrangeiras (analisados abaixo) procura estimar o valor destinado, por diversas instituições, à estruturação e manutenção de programas de compliance efetivos. Apenas para esclarecimento, os reports e surveys a serem analisados não tratam apenas de programas de compliance antitruste, e sim de programas de compliance latu senso, i.e., programas voltados para minoração tanto do risco da prática de condutas anticoncorrenciais, quanto do risco de cometimento de condutas proibidas por diversas outras leis (como, por exemplo, leis anticorrupção). Isso porque, na realidade, a implementação desse programa, geralmente, envolve a estruturação de um compliance que engloba diversas regulações (não só a concorrencial), o que se explica pelo escopo nas funções e na redução dos custos fixos associados à estrutura do programa ${ }^{33}$.

\footnotetext{
${ }^{31}$ No que diz respeito à autonomia e independência do programa, a autoridade francesa chega até a recomendar a criação de um corpo de administração voltado somente para o compliance, bem como a criação de um cargo de alto escalação (de diretoria/sênior) para o responsável pela implementação do programa de compliance.

${ }^{32}$ No que diz respeito à autonomia e independência do programa, a autoridade sul coreana chega até a recomendar a criação de um cargo de alto escalação (“Compliance Officer") para o responsável pela implementação do programa de compliance.

${ }_{33}$ Nesse sentido, o Guia CADE para Programas de Compliance ressalta que: "Um programa de compliance raramente abarcará a legislação pertinente a apenas um setor ou endereçará apenas um tipo de preocupação. O mais comum é que os programas tratem simultaneamente de diversos aspectos e diplomas normativos. "Nesse sentido, vide MINISTÉRIO DA JUSTIÇA. CONSELHO ADMINISTRATIVO DE DEFESA ECONÔMICA. Guia para Programas de Compliance. Brasília, 2016, p. 9. Disponível em:
} 
Conforme se verá mais detalhadamente abaixo, a análise desse conjunto de pesquisas sobre o compliance (especificamente o investigativo) permitiu identificar que, global e nacionalmente, a atual alocação de recursos das empresas para estruturação e manutenção de programas de compliance ainda é insuficiente. Muito embora tenha havido um movimento crescente de investimentos nesses programas ${ }^{34}$, fato é que os recursos destinados a eles, de acordo com as publicações exploradas, ainda não são suficientes para tornar as estruturas de conformidade efetivamente capazes de prevenir o cometimento de infrações e de, consequentemente, reduzirem as possibilidades de gastos com condenações progressivamente mais severas.

Em relação ao contexto nacional, a quantidade de recursos alocados, por empresas brasileiras, na estruturação e manutenção de programas de compliance pode ser bem observada através da figura, abaixo, retirada de pesquisa da consultoria KPMG:

\section{Figura 1: Orçamento anual dedicado à implementação de programas de compliance em 2016 (por segmento) $^{35}$}

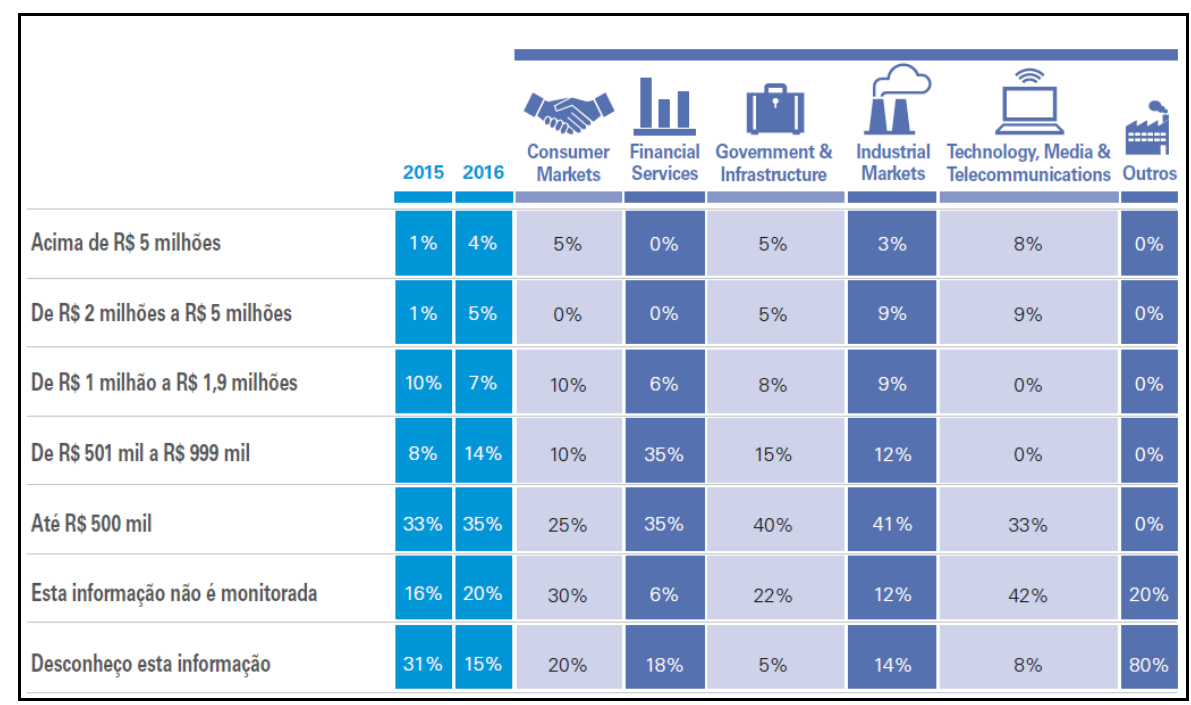

Fonte: Pesquisa Maturidade do Compliance no Brasil, KPMG, 2017

No caso, como se pode notar da figura 1, empresas nacionais de diversos segmentos aumentaram os gastos com compliance entre 2015 e 2016 (à exceção daquelas que investem na faixa de 1 a 1,9 milhões de reais). Entretanto, a mesma figura também revela que, muito embora tenha havido um movimento de aumento dos

<http://www.cade.gov.br/acesso-a-informacao/publicacoes-institucionais/guias_do_Cade/guia-compliance-versao-oficial.pdf>. Acesso em: 17/01/2018.

${ }^{34}$ Esse movimento, conforme se verá adiante, assume ritmos diferentes no Brasil em comparação com o resto do mundo. Enquanto já se é possível identificar uma possível redução esperada do mercado em investimentos com o compliance no exterior, no Brasil, ainda acontece um movimento de expansão dos gastos com programas de compliance.

35 KPMG. Pesquisa Maturidade do Compliance no Brasil, 2 edição, 2017. p.15. Disponível em: <https://home.kpmg.com/br/pt/home/insights/2017/01/pesquisa-maturidade-do-compliance-no-brasil-2a-edicao.html>. Acesso em 20/02/2018. 
gastos com o programa, grande parte das empresas (35\%) ainda investem na faixa mínima de quantidade de recursos (até R\$ 500 mil) estipulada pelo estudo, fator que pode ser chave para se entender uma segunda grande conclusão dessa mesma pesquisa: a de que o compliance no Brasil ainda carece de infraestruturas de alta performance capazes de tornar o programa realmente efetivo.

Em que pese seja possível se verificar um movimento de diminuição da quantidade de empresas sem qualquer tipo de infraestrutura dedicada ao compliance ${ }^{36}$, fato é que os programas de compliance das empresas entrevistadas ainda possuem baixíssimo grau de maturidade em relação a diversos temas específicos. Apenas para ficar com alguns exemplos, veja-se, na figura abaixo, como os programas ainda não atingiram um alto nível de efetividade ("alta performance") em diversos temas fundamentais atinentes a um compliance efetivo:

Figura 2: Grau de Maturidade dos Programas de Compliance no Brasil conforme a KPMG (2016)

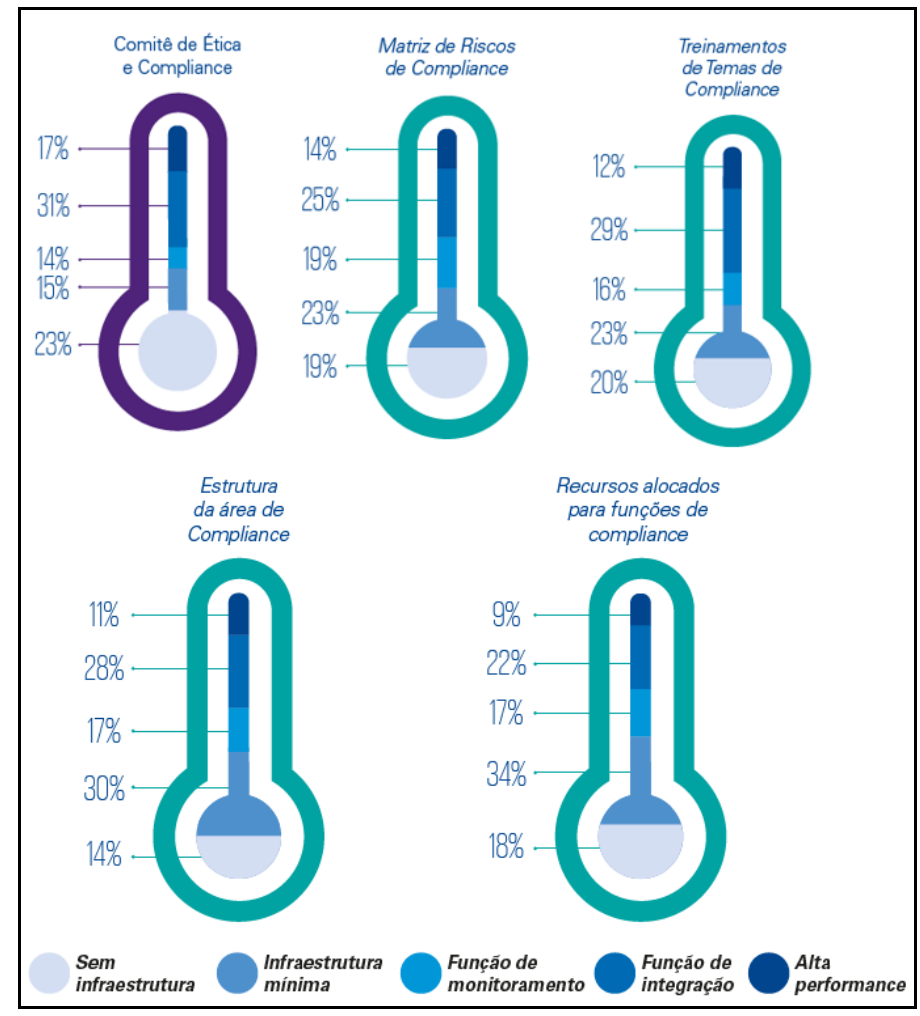

Fonte: Pesquisa Maturidade do Compliance no Brasil, KPMG, 2017

Note-se da figura acima que, em relação a todos os cinco temas exemplificados, a porcentagem de empresas que possuem programas de alta performance (efetivos) não chega a 20\%. Aliás, por outro ângulo, é

\footnotetext{
${ }^{36}$ Conforme a mesma pesquisa da KPMG, se, em 2015, 12\% das empresas entrevistadas não possuíam nenhuma infraestrutura de compliance, em 2016, esse número cai para 8\%. KPMG. Pesquisa Maturidade do Compliance no Brasil, 2 edição, 2017. p.11. Disponível em: <https://home.kpmg.com/br/pt/home/insights/2017/01/pesquisa-maturidade-do-compliance-no-brasil-2aedicao.html $>$. Acesso em 20/02/2018.
} 
possível se observar também que, ao menos em relação aos temas da existência de um comitê de ética/compliance e de realização de treinamentos, um número não desprezível de empresas (23\% e 20\%, respectivamente) sequer conta c om infraestrutura para lidar com esses assuntos.

Aliás, esse diagnóstico de imaturidade/inefetividade dos programas de compliance nacionais também é compartilhado por pesquisa (até mais recente) da consultoria Proviti. Conforme o índice de maturidade de compliance confeccionado internamente pela referida empresa, apenas $28 \%$ dos programas atingiriam índices médios para alto (ou seja, seriam programas efetivos), enquanto que a grande maioria deles (72\%) tem performance média ou muito abaixo da desejável (ou seja, seriam programas pouco, ou nada efetivos):

\section{Gráfico 6: Grau de Maturidade dos Programas de Compliance no Brasil conforme a Proviti} (2017)

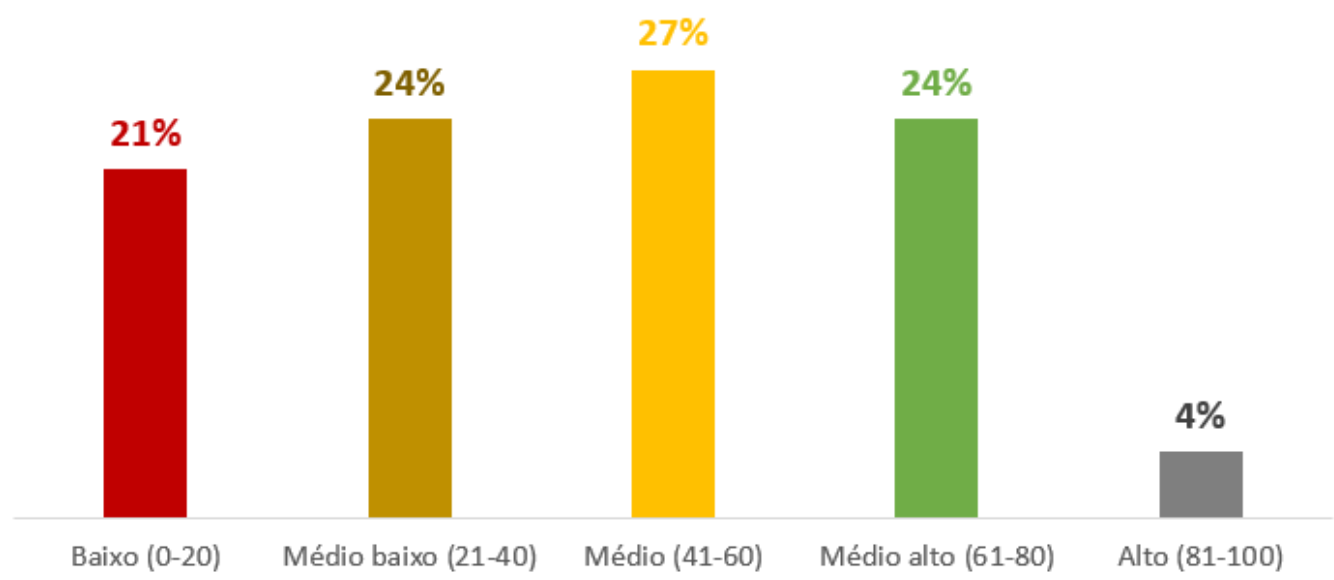

Fonte: Pesquisa Nível de Maturidade do Compliance das Organizações Brasileiras, 2017, Proviti

Já em relação ao contexto internacional, é possível se identificar diagnóstico semelhante ao panorama brasileiro, em que pese variação circunstancial. Embora, no plano global, os estudos demonstrem uma queda esperada e efetiva dos gastos com programas de compliance, essas mesmas pesquisas também se alinham às nacionais no sentido de que os programas estruturados ainda carecem de esforços que os tornem robustos e mais efetivos.

No que se refere à queda esperada dos gastos com compliance do ponto de vista externo, o gráfico, abaixo, retirado da publicação "Compliance Transformation Survey" da KPMG mostra bem em que medida as empresas creem gastar menos com os programas de compliance no próximo ano:

Gráfico 7: Evolução da expectativa dos entrevistados em relação a gastos com programas 


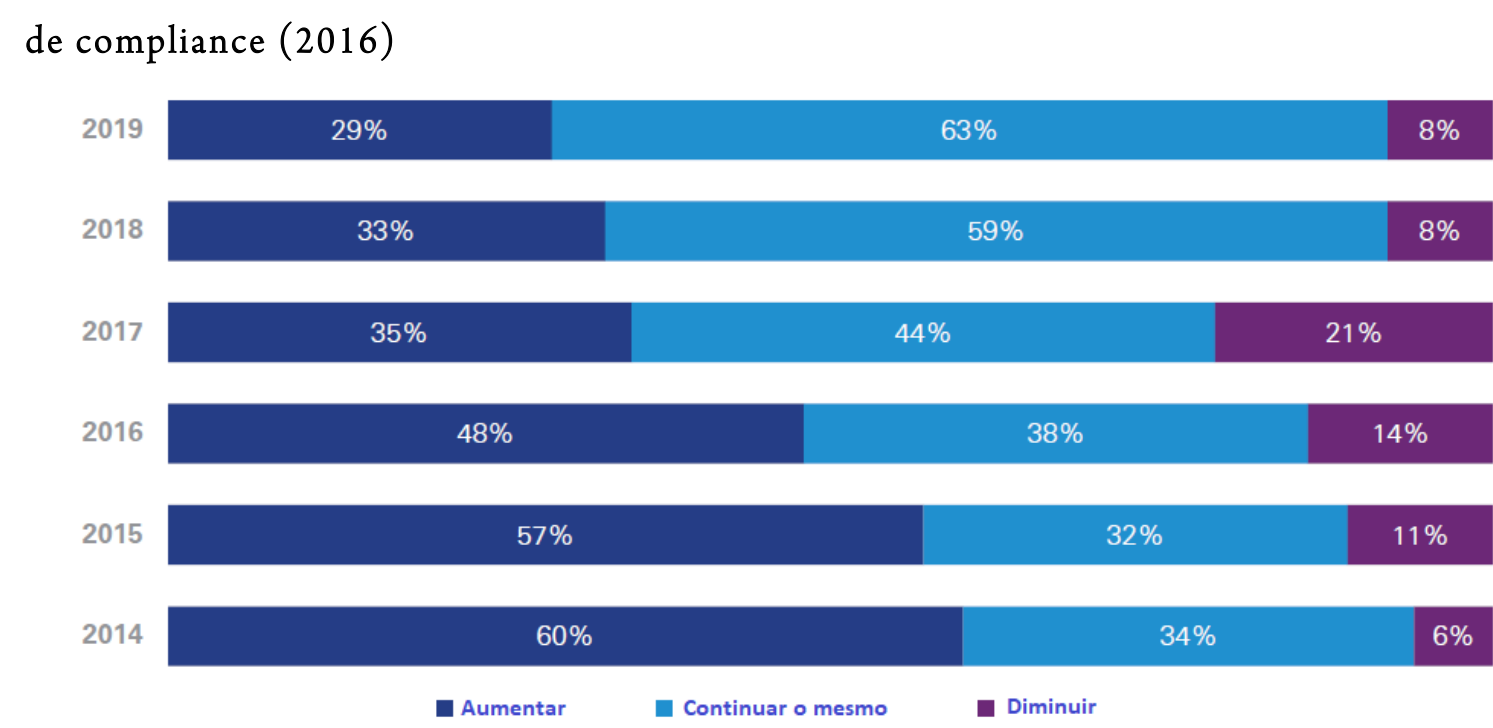

Fonte: Compliance Transformation Survey, KPMG International, 2016

Como se pode notar da observação do gráfico acima, as porcentagens relativas às pretensões de aumento dos gastos caíram ao longo de todos os anos analisados (inclusive em 2019). Na realidade, esse fenômeno também pode ser enxergado, na prática, ao se cruzar os dados desse mesmo estudo da KPMG com dados da pesquisa "International Business Attitudes to Compliance" da consultoria Control Risks. Nesse caso, enquanto a publicação "Compliance Transformation Survey" da KPMG estima as faixas de investimento das organizações mundiais entrevistadas com programas de compliance, em 2016, da seguinte forma:

Figura 3: Total de gastos com programas de compliance $(2016)^{37}$

\footnotetext{
${ }^{37}$ KPMG. 2016 Compliance Transformation Survey: How compliance leaders view their programs, Delaware, 2016. p. 23. Diponível em: <https://home.kpmg.com/be/en/home/insights/2017/02/2016-compliance-transformation-survey.html>. Acesso em 20/02/2018.
} 


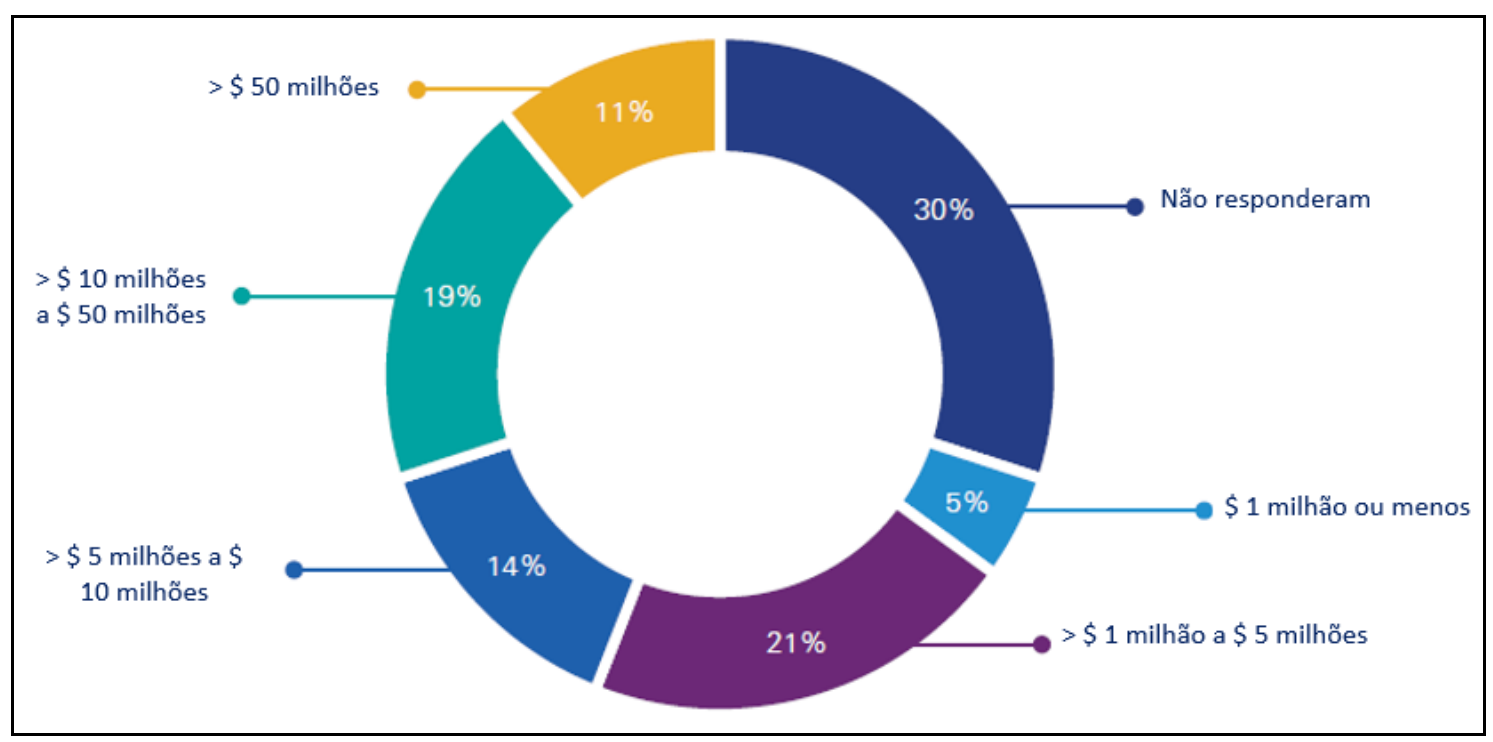

Fonte: Compliance Transformation Survey, KPMG International, 2016

O "International Business Attitudes to Compliance" da Control Risks, em contraste, estima investimentos mais tímidos dos entrevistados com programas de compliance no ano de 2017 :

Figura 4: Total de gastos com programas de compliance $(2017)^{38}$

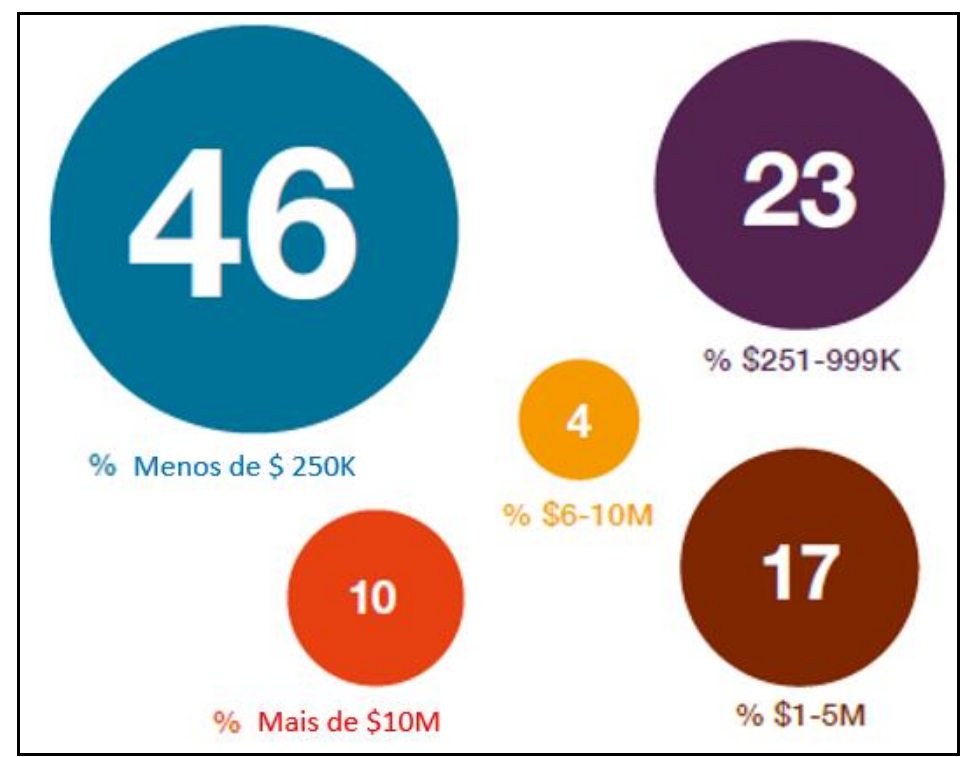

Fonte: International Business Attitudes to Compliance, Control Risks, 2017

Ademais, esse fenômeno da queda de investimentos também parece ser compartilhado por publicação internacional mais recente da KPMG "The compliance journey (2017)". Conforme esse estudo, se em 2014, cerca de 60\% dos entrevistados (diretores de compliance) informaram que o orçamento para compliance, em

38 CONTROL RISKS. International Business Attitudes to Compliance, Londres, 2017. p. X. Disponível em: $<$ https://www.controlrisks.com/our-thinking/insights/reports/international-business-attitudes-to-compliance>. Acesso em 20/02/2018. 
suas organizações, aumentou, em 2015 e 2016, essa porcentagem cai para 57\% e 48\%, respectivamente. Além disso, em relação a 2017, apenas cerca de um terço dos entrevistados esperavam aumentos contínuos nos orçamentos ${ }^{39}$.

Entretanto, em que pese um movimento de queda dos investimentos em compliance possa exprimir, em alguma medida, uma possível tendência de estabilidade e maturidade dessas estruturas, fato é que as publicações internacionais (assim como as nacionais) também destacam a baixa performance (ineficiência) dos programas de empresas estrangeiras em determinados aspectos. Apenas para se ficar com alguns números como exemplos, pesquisa da consultoria Delloite "Compliance Trends Survey" reportou, em 2016, que 21\% das empresas entrevistadas não possuem posições de diretoria para o tema compliance (e.g. Compliance Chief Officer) e que somente em $32 \%$ das empresas entrevistadas esse cargo teria independência e autonomia ${ }^{40}$. No mesmo fluxo, a pesquisa da KPGM "The Compliance Journey" expõe, por exemplo, que apenas 29\% das organizações entrevistadas realizam avaliação regular e periódica das habilidades dos funcionários com o programa de compliance $e^{41}$.

Curiosamente, as pesquisas consultadas concluem que, na realidade, as empresas ainda não estariam alocando quantidade suficiente de recursos para esses programas se tornarem de fato efetivos ${ }^{42}$. Assim, muito embora na prática seja possível se verificar uma tendência externa de queda do volume de investimentos para o compliance, fato é que esse movimento é causa e, ao mesmo tempo, é agravante da ainda ineficiência (em alguns aspectos) de programas de conformidade no contexto internacional.

Nesse caso, tendo em vista tudo o que fora exposto neste tópico, a conclusão a que se é possível chegar, após todas as análises feitas por este trabalho, é a de que (guardadas as devidas variações circunstanciais demonstradas) tanto no Brasil, como no exterior, em que pese seja possível se identificar uma tendência à adoção de programas de compliance investigativos, tal movimento ainda precisa passar por um processo de aperfeiçoamento e maturação de estruturas de compliance pouco efetivas. Certamente, esse estudo é de grande

\footnotetext{
${ }^{39}$ KPMG. The compliance journey: Boosting the value of compliance in a changing regulatory climate, Delaware, 2017 . p. 42. Disponível em: <https://advisory.kpmg.us/content/dam/kpmg-advisory/risk-consulting/pdfs/2017/03/compliance-journeysurvey.pdf $>$. Acesso em: 20/02/2018.

40 DELOITTE. Compliance Week - In Focus: 2016 Compliance Trends Survey, 2017. p.6. Disponível em: $<$ https://www2.deloitte.com/content/dam/Deloitte/us/Documents/governance-risk-compliance/us-advisory-complianceweek-survey.pdf>. Acesso em: 20/02/2018.

${ }^{41}$ KPMG. The compliance journey: Boosting the value of compliance in a changing regulatory climate, Delaware, 2017 . p. 3. Disponível em: <https://advisory.kpmg.us/content/dam/kpmg-advisory/risk-consulting/pdfs/2017/03/compliance-journeysurvey.pdf $>$. Acesso em: 20/02/2018.

${ }^{42}$ São as conclusões das pesquisas: CONTROL RISKS. International Business Attitudes to Compliance, Londres, 2017 . p. 5. Disponível em: <https://www.controlrisks.com/our-thinking/insights/reports/international-business-attitudes-to-compliance>. Acesso em 20/02/2018 e DELOITTE. Compliance Week - In Focus: 2016 Compliance Trends Survey, 2017. p.4. Disponível em: <https://www2.deloitte.com/content/dam/Deloitte/us/Documents/governance-risk-compliance/us-advisory-complianceweek-survey.pdf>. Acesso em: 20/02/2018.
} 
valia, principalmente, para chamar a atenção das autoridades e órgão públicos de enforcement no que se refere à existência de uma possível ausência de incentivos para adoção de programas de compliance efetivos, exceção feita a empresas que foram condenadas ou que firmaram acordos (já que nessas o risco de exposição seria maior em caso de reincidência). Na verdade, esse artigo também é de grande valia para o setor privado, na medida em que sinaliza, que os atuais recursos destinados à estruturação de programas de conformidade ainda são insuficientes para efetivamente prevenir e detectar infrações à legislação.

\section{CONCLUSÃO}

Em síntese, este artigo procurou endereçar dois questionamentos associados à identificação de uma suposta tendência à adoção de programas de compliance (especialmente os de caráter investigativo, como os antitruste e anticorrupção): (i) se existe uma tendência duradoura de adoção desses programas por parte do setor privado e (ii) se esse movimento é acompanhado da estruturação de programas realmente efetivos.

Em relação ao primeiro questionamento, foi possível identificar que o atual panorama de crescimento do risco regulatório concorrencial torna mais atrativa a implementação de programas de conformidade, na medida em que influencia diretamente o grau de benefícios atrelados a esse tipo de estrutura.

Não obstante, também foi possível se identificar que determinados benefícios que poderiam atuar como possíveis incentivos à adoção de programas efetivos (i.e, que possuem determinadas características que o tornam realmente capazes de endereçar o risco de cometimento de condutas ilegais) não são unanimidade entre agências antitruste, fato esse que, aliado a outros possíveis fatores (como os custos de implementação e ausência de incentivos claros associados à efetividade do programa), leva à conclusão de que o movimento pela adoção de programas de compliance ainda passa por um processo de maturação (tanto global, como nacional). No caso, uma conclusão como a que se chegou é bastante relevante, na medida em que servirá de termômetro para os agentes reguladores adequarem seus posicionamentos de forma a, a partir de então, induzir um movimento de qualificação dos programas de compliance, i.e. de criação de incentivos para que o mercado aloque recursos adequados à estruturação de programas, de fato, efetivos.

CONCORRENTIAL COMPLETION: COST AND BENEFIT RELATIONS AFTER LAVA-JATO

\section{Abstract}

The operation called "Car Wash" changed Brazil in several ways. One of these ways was the increase in business 
interest in the development of compliance programs capable of preventing and detecting illegal practices, mainly those related to cartels (a significant part of the schemes investigated). This article aims to investigate, firstly, whether this alleged development trend of programs, especially those aimed to prevent the commitment of antitrust violations is permanent, or if it is only an event motivated by a temporary high-impact police and regulatory operation and, secondly, to verify if this phenomenon came with the structuring of effective programs. The research concludes that, although there is indeed a current trend towards the adoption of this type of program, there is a need for (in Brazil and in the rest of the world) a process of improvement and maturation of compliance structures, which is why it argues that public authorities have not yet been able to gauge the right incentives to adopt effective compliance programs.

Keywords: Compliance Programs; Antitrust Risks; Cost; Benefits; Effective Programs.

\section{REFERÊNCIAS BIBLIOGRÁFICAS}

ALMUNIA, Joaquín. SPEECH/10/586 at Businesseurope \& US Chamber of Commerce Competition Conference. Bélgica. 2010. Disponível em: <http://europa.eu/rapid/press-release_SPEECH-10-586_en.htm>. Acesso em: 16/05/2017.

AUTORITÉ DE LA CONCURRENCE. Antitrust compliance programmes - Corporate tools for competing safely in competition marketplace. Paris, 2012, p. 10.

COMISSÃO EUROPEIA. Compliance matters: What companies can do better to respect EU competition rules. Luxembourg: Publications Office of the European Union, Europa, 2012. p 21. Disponível em: $<$ http://ec.europa.eu/competition/antitrust/compliance/index_en.html>.Acesso em: 16/05/2017.

COMPETITION BUREAU. Bulltin - Corporate Compliance Programs. Canadá, 2015. Disponível em: $<$ http://www.competitionbureau.gc.ca/eic/site/cb-bc.nsf/vwapj/cb-bulletin-corp-compliance-e.pdf/\$FILE/cbbulletin-corp-compliance-e.pdf>. Acesso em: 16/01/2018.

CONTROL RISKS. International Business Attitudes to Compliance, Londres, 2017. p. X. Disponível em: <https://www.controlrisks.com/our-thinking/insights/reports/international-business-attitudes-to-compliance>. Acesso em 20/02/2018.

DELOITTE. Compliance Week - In Focus: 2016 Compliance Trends Survey, 2017. Disponível em: <https://www2.deloitte.com/content/dam/Deloitte/us/Documents/governance-risk-compliance/usadvisory-compliance-week-survey.pdf>. Acesso em: 20/02/2018.

DINO. Cresce o número de empresas que adotam programas de Compliance em $\mathrm{BH}$, segundo pesquisa da Amcham. Terra. Publicado em: 13/09/2017Disponível em: https://www.terra.com.br/noticias/dino/cresce-onumero-de-empresas-que-adotam-programas-de-compliance-em-bh-segundo-pesquisa-daamcham,d7ff399829607578a190dbf3d8250587ylnirqs4.html. Acesso em: 27/01/2018.

FAIR TRADE COMISSION OF JAPAN. Corporate Compliance System - The present status and issues of the corporate compliance mainly with the Antimonopoly Act-(Summary). 2006. Disponível em: $<$ http://www.jftc.go.jp/en/policy_enforcement/survey/index.files/060524summary.pdf〉. Acesso em: 
$17 / 01 / 2018$.

ICC. Promoting Antitrust Compliance: The Various Approaches ff National Antitrust Authorities, 2011. Disonível em: <http://ec.europa.eu/competition/antitrust/compliance/icc_comparative_study_en.pdf >. Acesso em: 20/02/2018.

INTERNATIONAL CHAMBER OF COMMERCE. THE ICC ANTITRUST COMPLIANCE TOOLKIT: Practical antitrust compliance tools for SMEs and larger companies. 2013. Disponível em: $<$ https://iccwbo.org/publication/icc-antitrust-compliance-toolkit/>. Acesso em: 17/01/2018.

\section{KOREAN FAIR TRADE COMISSION. Rules On Operation OfFair Trade Compliance Programs, Offering Of} Incentives, $\quad$ Etc. $2016 . \quad$ Disponível em: http://www.ftc.go.kr/eng/cop/bbs/selectBoardList.do?key=526\&bbsId=BBSMSTR_000000002411\&bbsTy Code=BBST11. Acesso em: 17/01/2018.

KPMG. 2016 Compliance Transformation Survey: How compliance leaders view their programs, Delaware, 2016. p. 23. Diponível em: <https://home.kpmg.com/be/en/home/insights/2017/02/2016-compliancetransformation-survey.html>. Acesso em 20/02/2018.

KPMG. Pesquisa Maturidade do Compliance no Brasil, 2 edição, 2017. p.15. Disponível em: $<$ https://home.kpmg.com/br/pt/home/insights/2017/01/pesquisa-maturidade-do-compliance-no-brasil-2aedicao.html $>$. Acesso em 20/02/2018.

KPMG. The compliance journey: Boosting the value of compliance in a changing regulatory climate, Delaware, 2017. p. 42. Disponível em: <https://advisory.kpmg.us/content/dam/kpmg-advisory/riskconsulting/pdfs/2017/03/compliance-journey-survey.pdf>. Acesso em: 20/02/2018.

LACHNIT, Eva. Compliance Programmes in Competition Law: Improving the Approach of Competition Authorities. Utrecht Law Review, v.10, pp 31-50, 2014.

MELO, Luísa; ALVARENGA, Darlan. Compliance vira mercado em alta para escritórios de advocacia e consultorias. G1. Publicado em 09/07/2017. Disponível em: https://gl.globo.com/economia/negocios/noticia/compliance-vira-mercado-em-alta-para-escritorios-deadvocacia-e-consultorias.ghtml. Acesso em: 27/01/2018.

MINISTÉRIO DA JUSTIÇA. CONSELHO ADMINISTRATIVO DE DEFESA ECONÔMICA. Guia para Programas de Compliance. Brasília, 2016. Disponível em: <http://www.cade.gov.br/acesso-ainformacao/publicacoes-institucionais/guias_do_Cade/guia-compliance-versao-oficial.pdf>. Acesso em: 17/01/2018.

OFFICE OF FAIR TRADING. How your business can achieve compliance with competition law - Guidance. Londres, $2011 . \quad$ Disponível em: $<$ https://www.gov.uk/government/uploads/system/uploads/attachment_data/file/284402/oft1341.pdf>. Acesso em: 16/01/2018.

PARCU, Piere Luigi; STASI, Maria Luisa. Antitrust Compliance Programs in Europe: Status Quo and Challenges Ahead. In: Launch Workshop ENTraNCE for Executives, 2016, Florença. Disponível em: <http://cadmus.eui.eu/bitstream/handle/1814/39644/ENTraNCE_PB_2016_01.pdf?sequence=3>. Acesso 
em: 16/05/2017.

SUPERINTENDÊNCIA - GERAL (CADE). Balanço Anual 2017, 2018.

VANDENBORRE, Ingrid; GOETZ Thorsten. Compliance Programmes and Antitrust Fines. International Comparative Legal Studies, $2017 . \quad$ Disponível em: $<$ https://awards.concurrences.com/IMG/pdf/2_compliance_programmes_and_antitrust_fines.pdf >. Acesso em 16/05/2017.

Anexo 1: Benefícios atrelados à adoção de programas de compliance concorrencial

\begin{tabular}{|c|c|c|}
\hline $\begin{array}{c}\text { País/ } \\
\text { Autoridade }\end{array}$ & Título da Publicação & Benefícios do Compliance \\
\hline CADE (Brasil) & $\begin{array}{l}\text { Guia CADE para } \\
\text { Programas de } \\
\text { Compliance }\end{array}$ & $\begin{array}{l}\text { (1) Prevenção dos riscos atrelados à violação de lei } \\
\text { concorrencial; (2) Identificação antecipada de problemas; (3) } \\
\text { Reconhecimento de ilicitudes em outras organizações; (4) } \\
\text { Conscientização de funcionários; (5) Redução de custos e } \\
\text { contingências; (6) Melhora da reputação da empresa; (7) } \\
\text { Possível causa de redução de pena }{ }^{43} \text {. }\end{array}$ \\
\hline $\begin{array}{c}\text { Comissão } \\
\text { Europeia (EU) }\end{array}$ & $\begin{array}{l}\text { Compliance matters - } \\
\text { What companies can do } \\
\text { better to respect EU } \\
\text { competition rules }\end{array}$ & $\begin{array}{l}\text { (1) Prevenção quanto ao custo potencialmente elevado do não } \\
\text { cumprimento da legislação; (2) Melhora da reputação da } \\
\text { empresa; (3) Aumento da satisfação profissional e criação de um } \\
\text { sentimento de pertencimento em relação à empresa; (4) } \\
\text { Conscientização de funcionários; (5) Reconhecimento de } \\
\text { ilicitudes cometidas por terceiros; (6) Contribuição para garantir } \\
\text { a manutenção das condições de concorrência equitativas, } \\
\text { possibilitando levar irregularidades ao conhecimento das } \\
\text { autoridades e apresentação de pedidos de imunidade (leniência) } \\
\text { ou redução de pena (acordos) })^{44} \text {; (7) Identificação antecipada e, } \\
\text { consequentemente, freio de práticas ilícitas }{ }^{45} \text {. }\end{array}$ \\
\hline $\begin{array}{c}\text { Canada } \\
\text { (Competition } \\
\text { Bureau) }\end{array}$ & $\begin{array}{l}\text { Bulletin: Corporate } \\
\text { Compliance Programs }\end{array}$ & $\begin{array}{l}\text { (1) Manutenção de uma boa reputação (que, consequentemente } \\
\text { possibilitaria maior retenção de funcionários talentosos, bem } \\
\text { como de clientes valiosos); (2) Redução do risco do não } \\
\text { compliance; } \\
\text { (3) Identificação antecipada da prática de condutas } \\
\text { potencialmente ilegais; (4) Auxílio na qualificação da empresa } \\
\text { para um tratamento mais favorável em procedimentos }\end{array}$ \\
\hline
\end{tabular}

\footnotetext{
${ }^{43}$ MINISTÉRIO DA JUSTIÇA. CONSELHO ADMINISTRATIVO DE DEFESA ECONÔMICA. Guia para Programas de Compliance. Brasilia, 2016, 11-14. Disponível em: <http://www.cade.gov.br/acesso-a-informacao/publicacoesinstitucionais/guias_do_Cade/guia-compliance-versao-oficial.pdf $>$.Acesso em: 17/01/2018.

${ }^{44}$ COMISSÃO EUROPEIA. Compliance matters: What companies can do better to respect EU competition rules. Luxembourg: Publications Office of the European Union, Europa, 2012, p.p 9 e 10. Disponível em: $<$ https://publications.europa.eu/en/publication-detail/-/publication/78f46c48-e03e-4c36-bbbe-aa08c2514d7a/language-en>. Acesso em 17/01/2018.

${ }^{45}$ Ibidem, p.19.
} 


\begin{tabular}{|c|c|c|}
\hline & & $\begin{array}{l}\text { sancionadores; (5) Redução de custos relativos à litigância, } \\
\text { sanções, publicidade negativa e investigações da autoridade; (6) } \\
\text { Redução da exposição de funcionários e executivos à } \\
\text { responsabilização civil ou criminal; (7) Conscientização dos } \\
\text { funcionários acerca do curso de ação apropriado para responder } \\
\text { a solicitações da autoridade no curso de investigações; (8) } \\
\text { Auxílio adequado para empresas e seus funcionários em } \\
\text { negociações com a autoridade (por exemplo, através da } \\
\text { identificação de condutas ilegais em tempo de requerer leniência } \\
\text { ou imunidade); (9) Aumento da conscientização de } \\
\text { concorrentes, fornecedores e clientes acerca de comportamentos } \\
\text { possivelmente ilegais; (10) Possível causa de redução de pena }{ }^{46} \text {. }\end{array}$ \\
\hline $\begin{array}{l}\text { Office of Fair } \\
\text { Trading (Reino } \\
\text { Unido) }\end{array}$ & $\begin{array}{l}\text { How your business can } \\
\text { achieve compliance with } \\
\text { competition law }\end{array}$ & $\begin{array}{l}\text { (1) Prevenção quanto potenciais consequências negativas do } \\
\text { descumprimento da lei concorrencial; (2) Detecção antecipada } \\
\text { e, consequente, freio do cometimento de infrações; (3) } \\
\text { Capacitação de funcionários para o reconhecimento de infrações } \\
\text { cometidas por terceiros; (4) Aumento da confiança dos } \\
\text { funcionários quanto ao cumprimento da lei (que, } \\
\text { consequentemente, possibilita a empresa a competir de forma } \\
\text { mais vigorosa, além de capacitar os funcionários a identificarem } \\
\text { situações arriscadas que demandam orientação jurídica); (5) } \\
\text { Melhora da reputação da empresa } a^{47} \text {; (6) Possível causa de } \\
\text { redução (em até } 10 \% \text { ) de pena }{ }^{48} \text {. }\end{array}$ \\
\hline $\begin{array}{l}\text { Autorité de la } \\
\text { Concurrence } \\
\text { (França) }\end{array}$ & $\begin{array}{l}\text { Antitrust compliance and } \\
\text { compliance } \\
\text { programmes: Corporate } \\
\text { tools for competing } \\
\text { safely in the marketplace } \\
\qquad(2012)\end{array}$ & $\begin{array}{l}\text { (1) Aumento da capacidade de controle dos riscos de violação à } \\
\text { lei concorrencial; (2) Detecção antecipada e, consequente, freio } \\
\text { do cometimento de infraçães; (3) Prevenção quanto aos altos } \\
\text { custos do não cumprimento (sanções) das regras de } \\
\text { concorrência; (4) Melhora da reputação da empresa; (aumento } \\
\text { da confiança dos clientes na empresa além da criação de um } \\
\text { senso de lealdade nos funcionários); (5) Aumento da confiança } \\
\text { quanto ao cumprimento da lei, que, consequentemente, } \\
\text { possibilita a empresa crescer solidamente }{ }^{49} \text {. }\end{array}$ \\
\hline Turquia & $\begin{array}{l}\text { Letter OfThe President } \\
\text { OfTurkish Competition } \\
\text { Authority (2011) }\end{array}$ & $\begin{array}{l}\text { (1) Conscientização dos funcionários acerca de condutas } \\
\text { anticoncorrenciais; (2) Melhora da reputação da empresa; (3) } \\
\text { Identificação antecipada de problemas para evitar sanções }{ }^{50} \text {; }\end{array}$ \\
\hline
\end{tabular}

46 COMPETITION BUREAU. Bulltin - Corporate Compliance Programs. Canadá, 2015, p. 4. Disponível em: <http://www.competitionbureau.gc.ca/eic/site/cb-bc.nsf/vwapj/cb-bulletin-corp-compliance-e.pdf/\$FILE/cb-bulletin-corpcompliance-e.pdf $>$. Acesso em: 16/01/2018.

${ }^{47}$ OFFICE OF FAIR TRADING. How your business can achieve compliance with competition law - Guidance. Londres, 2011, $\begin{array}{llllll}\text { p.p } & 5 & \mathrm{e} & 6 . & \text { Disponível } & \mathrm{em} \text { : }\end{array}$ <https://www.gov.uk/government/uploads/system/uploads/attachment_data/file/284402/oft1341.pdf>. Acesso em: $16 / 01 / 2018$.

${ }^{48}$ Ibidem, p.32.

${ }^{49}$ AUTORITÉ DE LA CONCURRENCE. Antitrust compliance programmes - Corporate tools for competing safely in competition marketplace. Paris, $2012, \quad$ p. $\quad 5-7 . \quad$ Disponível em:<http://www.autoritedelaconcurrence.fr/doc/brochure_conformite_uk.pdf $>$. Acesso em: 16/01/2018.

${ }^{50}$ ICC. Promoting Antitrust Compliance: The Various Approaches ff National Antitrust Authorities, 2011. p.24. Disonível em: $<$ http://ec.europa.eu/competition/antitrust/compliance/icc_comparative_study_en.pdf >.Acesso em: 20/02/2018. 


\section{Anexo 2: Características essenciais de programas de compliance efetivos}

\begin{tabular}{|c|c|c|}
\hline $\begin{array}{c}\text { Autoridade/ } \\
\text { País }\end{array}$ & $\begin{array}{c}\text { Título da } \\
\text { Publicação }\end{array}$ & Características Essenciais \\
\hline CADE (Brasil) & $\begin{array}{c}\text { Guia CADE para } \\
\text { Programas de Compliance }\end{array}$ & $\begin{array}{l}\text { (1) Comprometimento (que se traduziria no envolvimento da } \\
\text { alta direção, na aplicação de recursos adequados e na existência } \\
\text { de autonomia e independência); (2) Mecanismos de análise } \\
\text { de riscos; (3) Mecanismos de mitigação de riscos } \\
\text { (documentação, realização de treinamentos, monitoramento, } \\
\text { mecanismos de delações e de punição); (4) Revisão periódica } \\
\text { do programa }{ }^{51} \text {. }\end{array}$ \\
\hline $\begin{array}{c}\text { Comissão } \\
\text { Europeia (EU) }\end{array}$ & $\begin{array}{l}\text { Compliance matters - } \\
\text { What companies can do } \\
\text { better to respect EU } \\
\text { competition rules }\end{array}$ & $\begin{array}{l}\text { (1) Existência de uma estratégia clara (consubstanciada em } \\
\text { mecanismos de identificação dos riscos, existência de } \\
\text { mecanismos de divulgação do programa por escrito e } \\
\text { envolvimento da alta direção); (2) Mecanismos de } \\
\text { identificação de condutas (oferecimento de manuais, } \\
\text { existência de mecanismos de punição e de delação); (3) } \\
\text { Atualização constante, além da criação de pontos de contato } \\
\text { para dúvidas e realização de treinamentos; (4) Mecanismos de } \\
\text { monitoramento e realização de auditorias }{ }^{52} \text {. }\end{array}$ \\
\hline $\begin{array}{l}\text { Competition } \\
\text { Bureau } \\
\text { (Canada) }\end{array}$ & $\begin{array}{l}\text { Bulletin: Corporate } \\
\text { Compliance Programs }\end{array}$ & $\begin{array}{l}\text { (1) Comprometimento (envolvimento da alta direção); (2) } \\
\text { Mecanismos de análise de riscos; (3) Existência de políticas e } \\
\text { procedimentos específicos (documentação, elaboração de } \\
\text { listas com descrição de práticas proibidas e permitidas, } \\
\text { estabelecimento de mecanismos de controle interno tais como } \\
\text { treinamentos prévios para determinadas situações com } \\
\text { concorrentes); (4) Realização de treinamentos e existência de } \\
\text { mecanismos de comunicação; (5) Mecanismos de } \\
\text { monitoramento, verificação e delação; (6) Existência de } \\
\text { procedimentos disciplinares e de incentivos para o } \\
\text { cumprimento do programa (mecanismos de punição para } \\
\text { quem descumpre o programa e de promoção para quem } \\
\text { cumpre o programa); (7) Revisão e avaliaçôes periódicas do } \\
\text { programa }\end{array}$ \\
\hline
\end{tabular}

\footnotetext{
${ }^{51}$ MINISTÉRIO DA JUSTIÇA. CONSELHO ADMINISTRATIVO DE DEFESA ECONÔMICA. Guia para Programas de Compliance. Brasilia, 2016, p. 15-29. Disponível em: <http://www.cade.gov.br/acesso-a-informacao/publicacoesinstitucionais/guias_do_Cade/guia-compliance-versao-oficial.pdf>.Acesso em: 17/01/2018.

${ }^{52}$ COMISSÃO EUROPEIA. Compliance matters: What companies can do better to respect EU competition rules. Luxembourg: Publications Office of the European Union, Europa, 2012, p. 16-19. Disponível em: $<$ https://publications.europa.eu/en/publication-detail/-/publication/78f46c48-e03e-4c36-bbbe-aa08c2514d7a/language-en>. Acesso em 17/01/2018.

${ }_{5333}$ COMPETITION BUREAU. Bulltin - Corporate Compliance Programs. Canadá, 2015. p.p. 10-22. Disponível em: $<$ http://www.competitionbureau.gc.ca/eic/site/cb-bc.nsf/vwapj/cb-bulletin-corp-compliance-e.pdf/\$FILE/cb-bulletin-corpcompliance-e.pdf $>$. Acesso em: 16/01/2018.
} 


\begin{tabular}{|c|c|c|}
\hline $\begin{array}{l}\text { Office of Fair } \\
\text { Trading (Reino } \\
\text { Unido) }\end{array}$ & $\begin{array}{l}\text { How your business can } \\
\text { achieve compliance with } \\
\text { competition law }\end{array}$ & $\begin{array}{l}\text { (1) Comprometimento (envolvimento da alta direção); (2) } \\
\text { Mecanismos de identificação de riscos; (3) Mecanismos de } \\
\text { análise de riscos (existência de mecanismos de rankeamento } \\
\text { dos riscos em alto, médio e baixo); (4) Mecanismos de } \\
\text { minoração do risco (criação de políticas e procedimentos } \\
\text { documentados; criação de um sistema de recompensas para } \\
\text { quem cumpre o programa, criação de mecanismos de delação } \\
\text { e realização de treinamentos); (5) Revisão periódica do } \\
\text { programa }\end{array}$ \\
\hline $\begin{array}{l}\text { Autorité de la } \\
\text { Concurrence } \\
\text { (França) }\end{array}$ & $\begin{array}{l}\text { Antitrust compliance and } \\
\text { compliance programmes: } \\
\text { Corporate tools for } \\
\text { competing safely in the } \\
\text { marketplace }(2012)\end{array}$ & $\begin{array}{l}\text { (1) Comprometimento (envolvimento da alta direção); (2) } \\
\text { Criação de um corpo de administração voltado somente para o } \\
\text { compliance (como, por exemplo, através da criação de um } \\
\text { cargo executivo de compliance); (3) Criação de medidas } \\
\text { relacionadas à informação, treinamentos e conscientização; (4) } \\
\text { Realização de auditorias e criação de mecanismos de delação; } \\
\text { (5) Criação de um sistema de monitoramento (que } \\
\text { compreende a criação de procedimentos para lidar com } \\
\text { pedidos de aconselhamento bem como a criação de } \\
\text { procedimentos de punição) } \\
\text { 55. }\end{array}$ \\
\hline $\begin{array}{l}\text { Korea Fair } \\
\text { Trade } \\
\text { Comission } \\
\text { (Coreia do Sul) }\end{array}$ & $\begin{array}{l}\text { Rules On Operation Of } \\
\text { Fair Trade Compliance } \\
\text { Programs, Offering Of } \\
\text { Incentives, Etc. }\end{array}$ & $\begin{array}{l}\text { (1) Declaração formal (escrita ou feita em cerimônia } \\
\text { específica) do CEO da empresa acerca do compromisso com } \\
\text { o compliance; (2) Designação de um “Compliance Officer" } \\
\text { para operar o programa; (3) Produção e distribuição de } \\
\text { manuais para o alto escalão e para o escalão operacional; (4) } \\
\text { Implementação de um sistema contínuo de educação voltado } \\
\text { para o compliance (criação de vídeos on-line a serem } \\
\text { reproduzidos ao menos } 2 \text { horas bianualmente); (5) } \\
\text { Estabelecimento de um sistema interno de supervisão (6) } \\
\text { Mecanismos de sanção; (7) Confecção de documentos } \\
\text { específicos para programa }{ }^{56} \text {. }\end{array}$ \\
\hline $\begin{array}{c}\text { Fair Trade } \\
\text { Commission of } \\
\text { Japan (Japão) }\end{array}$ & $\begin{array}{l}\text { Corporate Compliance } \\
\text { System - The present } \\
\text { status and issues of the } \\
\text { corporate compliance } \\
\text { mainly with the }\end{array}$ & $\begin{array}{l}\text { (1) Comprometimento (envolvimento da alta direção); (2) } \\
\text { Criação de um sistema de monitoramento efetivo; (3) Criação } \\
\text { de mecanismos de aperfeiçoamento da ética corporativa; (4) } \\
\text { Criação de um sistema de controle interno efetivo; (5) Criação } \\
\text { de mecanismos de punição }{ }^{57} \text {. }\end{array}$ \\
\hline
\end{tabular}

${ }^{54}$ OFFICE OF FAIR TRADING. How your business can achieve compliance with competition law - Guidance. Londres, 2011. p.10. Disponível em: <https://www.gov.uk/government/uploads/system/uploads/attachment_data/file/284402/oft1341.pdf>. Acesso em: 16/01/2018.

${ }^{55}$ AUTORITÉ DE LA CONCURRENCE. Antitrust compliance programmes - Corporate tools for competing safely in

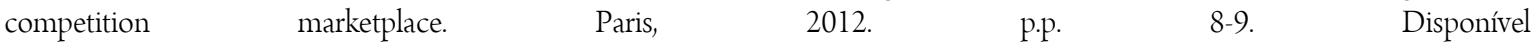
em:<http://www.autoritedelaconcurrence.fr/doc/brochure_conformite_uk.pdf>.Acesso em: 16/01/2018.

${ }^{56}$ KOREAN FAIR TRADE COMISSION. Rules On Operation Of Fair Trade Compliance Programs, Offering Of Incentives, Etc. $2016 . \quad$ p.5. Disponível em: http://www.ftc.go.kr/eng/cop/bbs/selectBoardList.do?key=526\&bbsId=BBSMSTR_000000002411\&bbsTyCode=BBST11. Acesso em: 17/01/2018.

${ }^{57}$ FAIR TRADE COMISSION OF JAPAN. Corporate Compliance System — The present status and issues of the corporate compliance mainly with the Antimonopoly Act- (Summary). 2006. p.3. Disponível em: <http://www.jftc.go.jp/en/policy_enforcement/survey/index.files/060524summary.pdf>.Acesso em: 17/01/2018. 


\begin{tabular}{|c|c|c|}
\hline & $\begin{array}{l}\text { Antimonopoly Act } \\
\text { (Summary) }\end{array}$ & \\
\hline Turquia & $\begin{array}{c}\text { Letter OfThe President Of } \\
\text { Turkish Competition } \\
\text { Authority }(2011)\end{array}$ & $\begin{array}{l}\text { (1) Comprometimento (envolvimento da alta direção); (2) } \\
\text { Criação de políticas e procedimentos adequados (que } \\
\text { envolvem, por exemplo, a criação de manuais e guias, além da } \\
\text { exigência de termos de compromisso dos empregados com o } \\
\text { compliance); (3) Realização contínua de treinamentos; (4) } \\
\text { Criação de um processo sistemático de análise (que envolve o } \\
\text { exame constante do nível de aprendizado dos empregados } \\
\text { acerca do programa); (5) Criação de um sistema de } \\
\text { penalidade/incentivos; (6) Revisão periódica do programa }{ }^{58} \text {. }\end{array}$ \\
\hline
\end{tabular}

Fonte: elaboração própria

Trabalho enviado em 06 de março de 2018.

Aceito em 16 de abril de 2018.

${ }^{58}$ ICC. Promoting Antitrust Compliance: The Various Approaches ff National Antitrust Authorities, 2011. p. 7-8. Disponível em: $<$ http://ec.europa.eu/competition/antitrust/compliance/icc_comparative_study_en.pdf >. Acesso em: 20/02/2018. 